Eukaryotic initiation factors (elFs). Protein factors or complexes found in eukaryotes, the primary function of which is in stabilizing the formation of ribosome-containing complexes and properly positioning these complexes at the start codon during translation initiation.

Innate immune response A set of immediate cellular responses that detects infection and then triggers a variety of pathways designed to limit infection. This response is not specific to the identity of the infectious agent and includes molecular events that affect translation (such as

phosphorylation of the $\alpha$-subunit of eukaryotic initiation factor 2).

'Department of Biochemistry and Molecular Genetics,

University of Colorado Denver School of Medicine, Aurora, CO, USA.

${ }^{2} R N A$ Bioscience Initiative, University of Colorado Denver School of Medicine, Aurora, CO, USA.

*e-mail: jeffrey.kieft@ ucdenver.edu

\title{
Viral RNA structure-based strategies to manipulate translation
}

\author{
Zane A. Jaafar ${ }^{1}$ and Jeffrey S. Kieft $\mathbb{B}^{1,2 *}$
}

Abstract | Viruses must co-opt the cellular translation machinery to produce progeny virions. Eukaryotic viruses have evolved a variety of ways to manipulate the cellular translation apparatus, in many cases using elegant RNA-centred strategies. Viral RNAs can alter or control every phase of protein synthesis and have diverse targets, mechanisms and structures. In addition, as cells attempt to limit infection by downregulating translation, some of these viral RNAs enable the virus to overcome this response or even take advantage of it to promote viral translation over cellular translation. In this Review, we present important examples of viral RNA-based strategies to exploit the cellular translation machinery. We describe what is understood of the structures and mechanisms of diverse viral RNA elements that alter or regulate translation, the advantages that are conferred to the virus and some of the major unknowns that provide motivation for further exploration.

Eukaryotic translation is complex, occurring in four phases: initiation, elongation, termination and recycling (FIG. 1). During the initiation phase, the combined effort of more than a dozen eukaryotic initiation factors (eIFs) brings the $40 \mathrm{~S}$ and $60 \mathrm{~S}$ ribosomal subunits to the mRNA and positions the ribosome and the initiator methionine tRNA (Met-tRNA ${ }_{i}{ }^{\mathrm{et}}$ ) at the start codon ${ }^{1}$. Initiation is followed by elongation, in which the ribosome actively moves along the mRNA, using tRNAs and eukaryotic elongation factors (eEFs) to synthesize protein ${ }^{2}$. Termination occurs when the elongating ribosomal complex reaches the stop codon and the stop codon is recognized by eukaryotic release factors (eRFs) eRF1 and eRF3. The peptide, mRNA and tRNA are then released and subunit dissociation is promoted by eRFs and other factors, permitting the released subunits to be recycled and to participate in another round of translation ${ }^{2,3}$.

The complexity of the eukaryotic translation cycle provides for precise regulation but also allows eukaryotic viruses to exploit or manipulate the process. To counter this, cells have evolved mechanisms for detecting viral infection and then altering the translation capacity of the cell. Specifically, cells can recognize pathogen-associated molecular patterns (PAMPs; for example, double-stranded RNA or 5 ' triphosphorylated RNAs) or they can be stimulated by outside signals (for example, interferons), resulting in the activation of the innate immune response, which can lead to a programmed decrease in translational capacity aimed at limiting the production of viral proteins ${ }^{4}$. This decrease in translation is primarily achieved by inhibiting translation initiation, either by interfering with the delivery of Met-tRNA ${ }_{i}{ }^{\text {eet }}$ through phosphorylation of eIF2 $\alpha$ or the recruitment of ribosomes to mRNAs by sequestering eIF4E. In turn, viruses have evolved ways to overcome or even exploit these antiviral defences to promote viral protein synthesis. Many eukaryotic viruses employ protein-based mechanisms that manipulate the cellular translation machinery or subvert antiviral responses ${ }^{5,6}$ (BOX 1), but many other mechanisms depend on structured viral RNA elements. As the genomes of positive-sense RNA viruses are the templates for translation, these genomes are a rich repository of functional RNA elements that manipulate the cellular translation machinery, even before viral proteins accumulate. However, RNA elements that manipulate the translation machinery are found in diverse eukaryotic viruses and throughout viral genomes, highlighting their importance for viral infection.

The number and variety of viral RNA-based strategies used to manipulate translation (reviewed in REF.') is too great to comprehensively discuss all of them and their detailed mechanisms in this Review. Thus, we refer the reader to other, more focused reviews where necessary. In this Review, we focus on illustrative examples that conceptually reveal the diversity of RNA structurebased mechanisms for manipulating translation. The Review is organized to follow the phases of translation, starting with initiation at the $5^{\prime}$ end and progressing to termination at the $3^{\prime}$ end of viral RNAs. We first describe examples of how viruses use RNA-based strategies to exploit or mimic canonical translation initiation processes, then present examples of viral RNAs that 


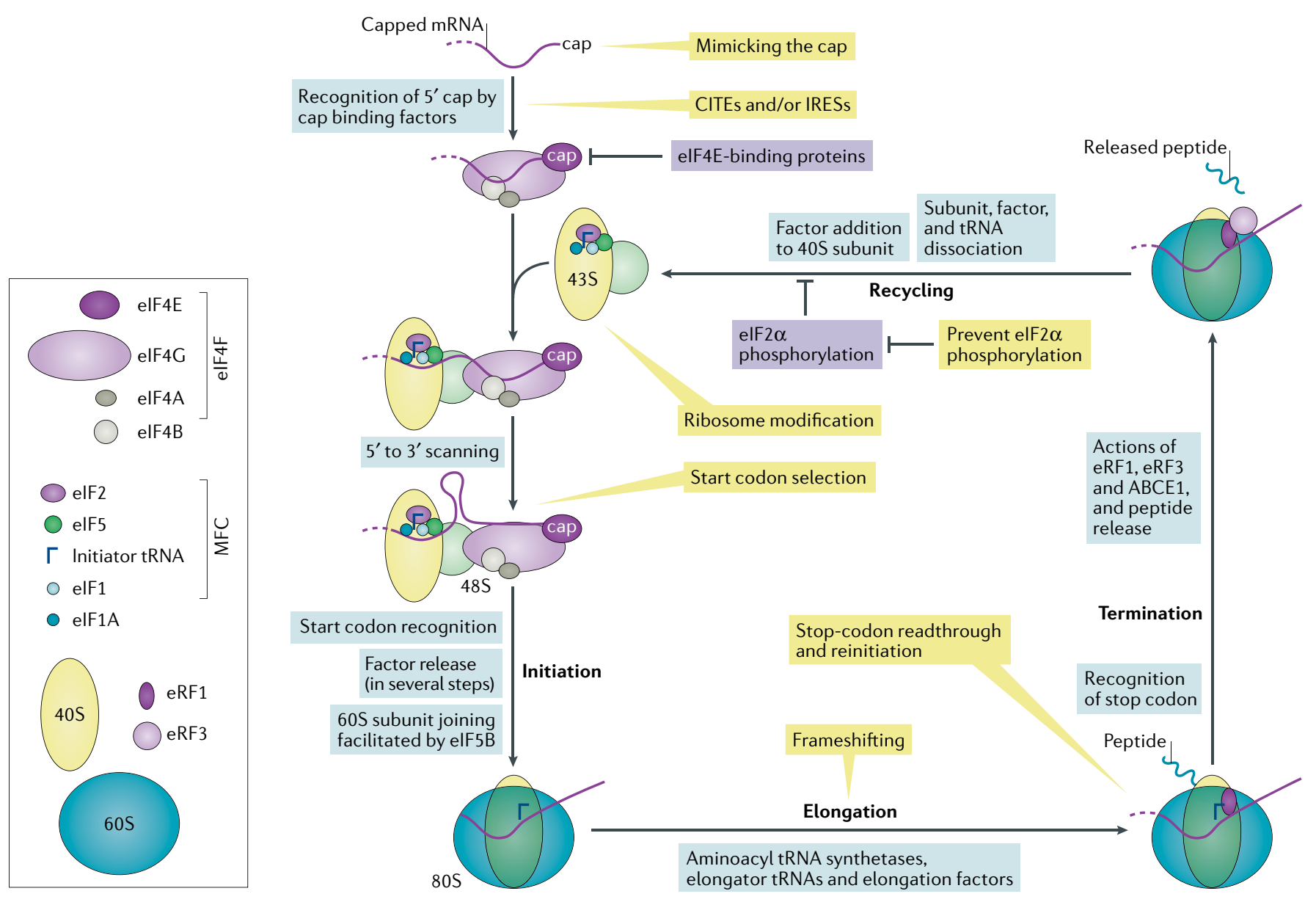

Fig. 1 Antiviral responses involving translation and viral RNA-based strategies to manipulate translation. The translation cycle is generally divided into four phases, depicted here. For clarity, details such as each GTP hydrolysis event, all involved factors and individual steps are not shown; further details can be found in REFS ${ }^{1-3}$. Briefly, during canonical cap-dependent eukaryotic translation initiation, mRNA is recognized by the eukaryotic initiation factor (elF) elF4F complex, which contains elF4E, elF4G and elF4A. This complex binds the modified nucleotide cap on the $5^{\prime}$ end of the mRNA, resulting in an mRNA activated for translation. A series of intermolecular recognition events leads to recruitment of the $43 \mathrm{~S}$ complex to this activated mRNA; the $43 \mathrm{~S}$ complex contains the small (40S) ribosomal subunit, elFs (elF3, elF1, elF1A and eIF5) and the eIF2-Met-tRNA Met-GTP ternary complex. Next, the mRNA sequence is scanned in a 5' to $3^{\prime}$ direction by the ribosomal subunit and associated factors in an ATP hydrolysis-dependent process. During scanning, elF2-bound GTP is hydrolysed (stimulated by elF5). The purpose of this scanning is to locate the proper start codon; the most used is an AUG triplet. When a start codon is selected, a codon-anticodon interaction is formed with Met-tRNA ${ }_{i}^{\text {Met }}$ in the $\mathrm{P}$ site, forming the $48 \mathrm{~S}$ preinitiation complex. Phosphate is released by elF2 and conformational changes involving a number of elFs (elF2, elF1A, elF1 and elF5B) and a second GTP hydrolysis event on elF5B lead to the release of most protein factors and the joining of the large $(60 \mathrm{~S})$ ribosome subunit, creating an elongation-competent $80 \mathrm{~S}$ ribosome. During elongation, codons are read by aminoacylated tRNAs delivered by the eukaryotic elongation factor (eEF) eEF1A in a GTP hydrolysis-dependent process. As tRNAs decode the message and enter the ribosome, they deliver their cognate amino acid to the growing polypeptide chain. Formation of each peptide bond is followed by GTP hydrolysis-dependent translocation by eEF2 and delivery of the next tRNA. Once a peptide chain has been made, the ribosome must terminate protein synthesis, release the protein and allow the ribosome to be used again (recycling). Once a stop codon (UAA, UGA or UAG) enters the A site, it is recognized by eukaryotic release factors (eRFs). The action of the eRFs along with other factors, including ATP-binding cassette sub-family E member 1 (ABCE1), ligatin and potentially others, leads to release of the peptide, subunit dissociation, tRNA release and ribosome recycling. During recycling, protein factors needed for the next round of translation are loaded back onto the ribosomal subunits; these include the proteins that make up the multifactor complex (MFC). Most phases of translation can be regulated, but two specific phases are noteworthy owing to their effect during viral infection, shown in purple boxes. The first is to interrupt the process of mRNA recruitment through the cap, primarily through the inactivation of elF4E by hypophosphorylation of the factor or sequestration by elF4Ebinding proteins 1 and 2 . The second is by inhibiting initiator tRNA delivery by phosphorylation of the $\alpha$-subunit of elF2. This prevents exchange of GDP for GTP on the factor; thus, it cannot be used to deliver initiator tRNA. Specific kinases do this in response to stresses induced by many viral infections, the most common being sensing of double-stranded RNA viral replication intermediates or endoplasmic reticulum stress by viral replication complexes ${ }^{4}$. Viruses use RNA to interact with and exploit the translation process at many steps; examples that are discussed in this Review are shown in yellow boxes. CITE, cap-independent translation element; IRES, internal ribosome entry site. 


\section{5 ' end}

The end of a nucleic acid that

terminates in a functional group attached to the fifth

carbon of a ribose sugar.

3 ' end

The end of a nucleic acid that

terminates in a functional group attached to the third

carbon of a ribose sugar. drive non-canonical modes of initiation. Next, we discuss how elongation and termination processes can be manipulated by viral RNAs, then end with some interesting examples of structures in viral 3' UTRs that enable viruses to interact with the translation machinery in novel ways.

\section{Canonical translation initiation}

Modification of the 5' terminus to mimic host mRNAs. Perhaps the most straightforward way for a viral RNA to co-opt the cellular translation machinery is to directly mimic cellular mRNA translation initiation signals. There are several ways viruses enzymatically create a cap-like structure at the $5^{\prime}$ end of the viral RNA (reviewed in REFS ${ }^{8,9}$ ): using the host capping machinery in the nucleus, used by many double-stranded DNA viruses; encoding viral capping enzymes that are used in the cytoplasm; and through 'cap-snatching', in which the viral RNA polymerase cleaves the capped 5 ' end of nascent cellular mRNAs and uses this to prime viral RNA synthesis. This was first discovered in influenza A virus ${ }^{10}$; novel examples were recently reported for two totiviruses ${ }^{11,12}$. Some viruses further chemically modify the cap to mask viral RNAs from detection and degradation ${ }^{13,14}$. Although capping is a common way for viruses to hijack the cellular machinery, many viruses use cap-independent modes of translation initiation.

\section{Box 1 | Viral proteins that manipulate translation}

Viruses have evolved many mechanisms of altering translation or overcoming cellular translation inhibition in response to infection (see the figure). These mechanisms can inhibit translation of cellular mRNAs or promote the translation of viral RNAs. Viral proteins have been suggested to target virtually every component of the translation machinery and upstream signalling pathways; here we present a few examples, focused mainly on translation initiation, and direct the reader to recent reviews for reference and more explanation ${ }^{5,6}$. Viral proteins can proteolytically cleave eukaryotic initiation factors (elFs) or sequester them by direct binding. For example, the enterovirus 2A, which cleaves elF4G and poly(A) binding protein (PABP), and $3 \mathrm{C}$, which cleaves elF5B PABP, limit cellular translation. In addition, elF3 is targeted by the foot-and-mouth disease virus protease. Vesicular stomatitis virus (VSV) and reoviruses manipulate elF4E binding protein 1 (4EBP1) kinases to sequester elF4E and simian virus 40 (SV40) manipulates protein phosphatase PP2A, ultimately leading to sequestered non-functional elF4E. Influenza virus, VSV and adenoviruses produce proteins that bind elF4G and displace MAP kinase-interacting serine/threonineprotein kinase 1 (MNK1; also known as MKNK1), leading to a decrease in phosphorylated, functional elF4E. Viral proteins can also target cellular mRNAs. For example, the herpes simplex virus (HSV)-1 virion host shutoff protein (Vhs) targets cellular mRNAs for endoribonucleolytic cleavage, whereas the vaccinia virus D10 protein decaps mRNAs, resulting in cellular mRNAs that cannot initiate translation. Some viruses use proteins to alleviate translation inhibition, including mechanisms involving binding directly to translation factors to recruit them for viral translation or to block their inhibition. Many herpesviruses, adenoviruses, hepatitis $\mathrm{C}$ virus (HCV) and human papilloma virus indirectly promote the phosphorylation of 4EBP1 during infection to counteract regulation of elF4E. In addition, the ribonucleotide reductase large subunit (ICP6) of HSV-1 binds elF4G to enhance elF4F assembly. Interestingly, human cytomegalovirus (HCMV), through unknown mechanisms, can enhance the overall expression of elFs. Viral proteins also can specifically interact with distinct elFs to stimulate viral RNA translation. Cauliflower mosaic virus encodes two proteins that bind both elF3 and the ribosomal protein $\mathrm{L} 24$, thus tethering $40 \mathrm{~S}$ and $60 \mathrm{~S}$ subunits to promote translation, whereas noroviruses (and other viruses) use viral protein genome-linked (VPg) protein to bind elF4G to recruit viral RNA for translation. Non-essential virulence proteins, such as nonstructural protein 1 (NS1) from influenza virus, can bind elFs such as elF4G to stimulate viral translation, and many viruses are known to produce proteins that bind to or cleave the interferon-induced RNA-dependent elF2 $\alpha$ kinase (PKR) to block the phosphorylation of elF2 $\alpha$.
Promote viral translation

Bind elF4E with mRNA-
linked or mRNA-
associated proteins
(for example, VPg)
Bind elF4G and
manipulate elF4F
assembly and stability
(for example,
influenza virus NS1
and HSV-1 ICP6)
Interact with eIF3 to
direct viral mRNA
to $43 \mathrm{~S}$ (for example,
calicivirus VPg)

HCV NS5A)

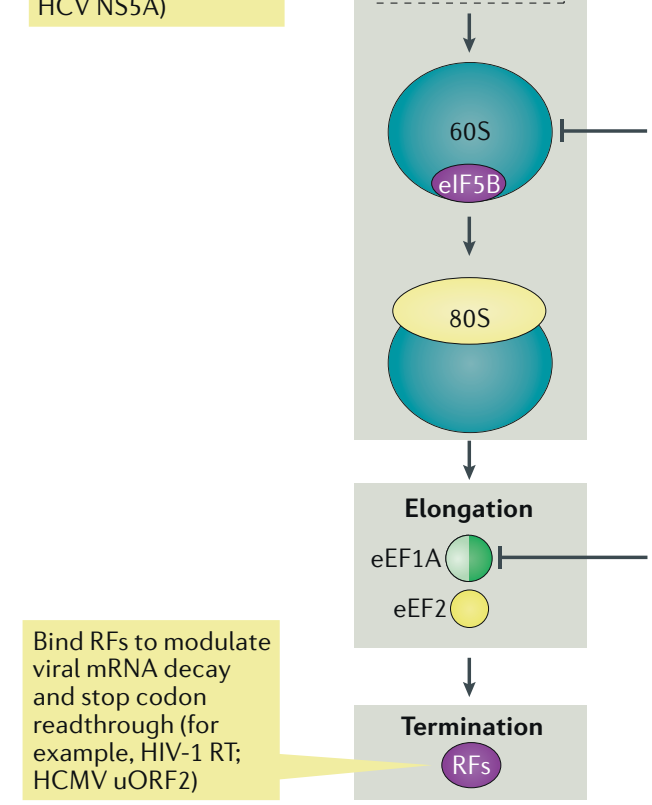

Inhibit cellular translation

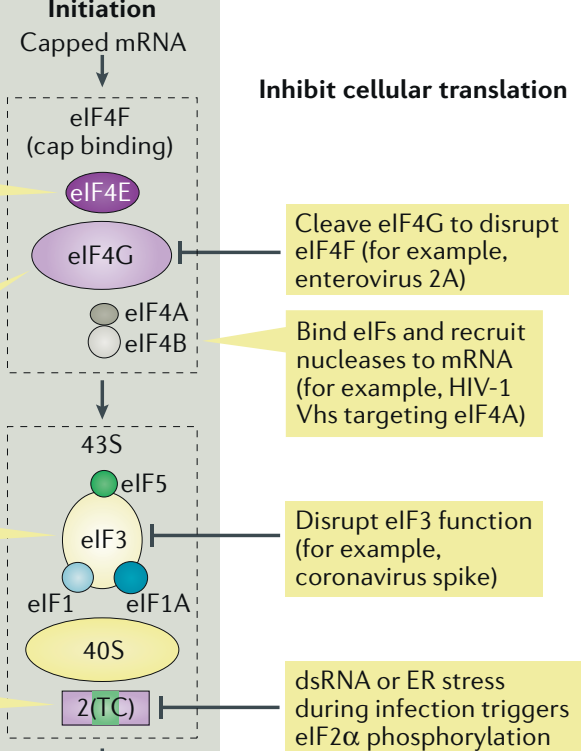

Cleave eIF5B

(for example, enterovirus $3 \mathrm{C}$ )

dsRNA, double-stranded RNA; eEF1, eukaryotic elongation factor 1; ER, endoplasmic reticulum;

NS5A, non-structural protein 5A; RFs, release factors; RT, reverse transcriptase; uORF2, upstream ORF initiated by AUG-2. 

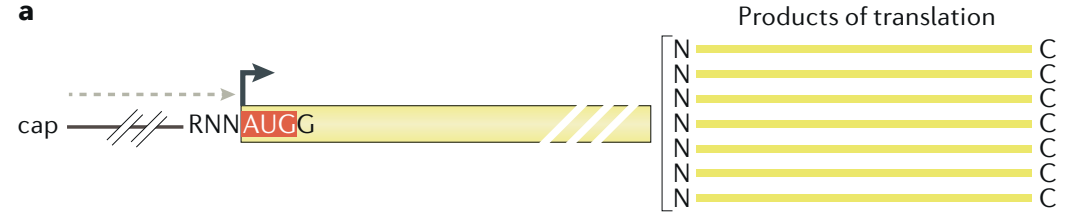

b
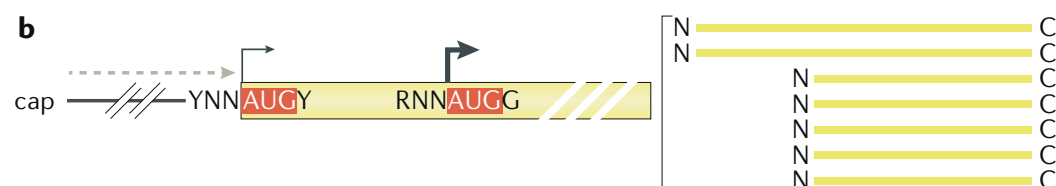

C

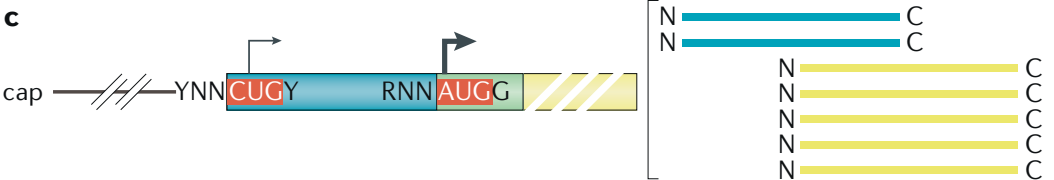

Fig. 2 | Variations on scanning and start codon recognition. Manipulation of the scanning and start codon recognition process by RNA sequence and structure is a strategy used by viruses to affect translation at the initiation phase and produce different proteins in different amounts. a $\mid$ A canonical cellular message that is 7-methylguanosinecapped (cap) and has an AUG in a strong Kozak context is shown. Ribosomes scan (grey dashed line) until they reach this AUG, where translation of the ORF (pale yellow) begins, as shown with the thick black arrow. This mechanism results in efficient production of a single protein product (yellow, to the right). $\mathbf{b}$ | Leaky scanning can occur when multiple codons exist with different context strengths. In this conceptual diagram, ribosomes scan and then encounter a start codon in a weak context (shown here with pyrimidines $(\mathrm{Y})$ at the -3 and +4 positions). Some ribosomes stop here and initiate, shown with the thin black arrow. Other ribosomes bypass this upstream AUG and continue scanning to reach a downstream AUG in a strong context and then initiate there. The amount of initiation at each AUG is dictated by the context strength. Two AUGs in the same reading frame are shown, leading to a longer and shorter isoform of the same protein, and the resultant population of protein products is shown to the right. $\mathrm{c}$ | Non-AUG codons can be used for initiation. An upstream alternative ORF is shown in blue, which is translated if scanning ribosomes initiate at a CUG in a weak context. Ribosomes that do not initiate at this CUG continue scanning to a downstream AUG in a strong context (pale yellow ORF). In the example shown here, the two ORFs overlap but are in different reading frames (green), leading to two entirely different protein products (right). Various combinations of overlapping reading frames in different contexts and start codons of different types and strengths can give rise to diverse outcomes in terms of types and relative amounts of protein, all from a single RNA template.

\section{Canonical translation initiation \\ A eukaryotic-specific translation initiation pathway that operates on an mRNA that has been post-transcriptionally modified to include an extra methylated nucleotide at its 5 ' end. Binding of this modified nucleotide by a protein begins the process of initiation.}

\section{Initiator tRNA}

A structurally and functionally distinct tRNA responsible for delivering the first amino acid (methionine) to the ribosome It binds in the P site of the ribosome, has an anticodon complementary to AUC and is used for initiation of the vast majority of proteins. It is not used during the elongation phase of translation.
Exploiting scanning and start codon selection. In canonical eukaryotic translation initiation, recruitment of the $43 \mathrm{~S}$ ribosomal complex to mRNAs is followed by $5^{\prime}$ to $3^{\prime}$ scanning to find a start codon; this process is readily exploited by viruses using RNA-based signals. The most used start codon is an AUG within a consensus sequence known as the Kozak sequence (FIG. 2a). A 'strong' Kozak consensus sequence is gccRccAUGG, in which the start AUG is surrounded by highly conserved nucleotides (uppercase letters; a purine (R) three nucleotides upstream of the AUG and a G immediately downstream of the AUG) and less conserved nucleotides (lowercase letters); variations on this provide various degrees of translation efficiency, or 'strength' ${ }^{15}$. If a start codon within a 'weak' Kozak sequence is encountered, scanning ribosomes can sometimes continue scanning, or 'leak', past the AUG codon to locate another start codon (FIG. 2b). This leaky scanning allows the production of different proteins in specific quantities from a single mRNA, and by shifting the reading frame to different start codons, different proteins can be synthesized (FIG. 2c). Viruses exploit this by using RNA templates that contain multiple reading frames, each starting at an AUG within a Kozak sequence of a specific strength, thus regulating the degree to which each codon is used for initiation. Notable mammalian viruses that use this include influenza $A$ and $B$ viruses and orthoreoviruses. A recently described example is in Andes virus, in which leaky scanning produces both the nucleocapsid protein and the non-structural protein from a single small mRNA ${ }^{16}$.

Ribosome profiling has uncovered a large number of non-AUG start codons (especially CUG) that are likely used to regulate gene expression ${ }^{17}$, and viruses can combine non-AUG initiation with start codon context 'strength' to provide precise regulation. For example, in panicum mosaic virus (PMV) infection, up to four ORFs are translated from a single subgenomic viral RNA using a combination of leaky scanning and initiation at GUG codons ${ }^{18}$. Furthermore, some viruses manipulate scanning and start site selection by encoding RNA signals that cause a scanning ribosome to 'shunt' over sections of the $5^{\prime}$ UTR that possibly contain short ORFs ${ }^{19}$. Another strategy of manipulating ribosome scanning is used by some alphaviruses when a subgenomic RNA (sgRNA) is translated under conditions of translation inhibition by elF2 a phosphorylation. Specifically, a stable RNA stem-loop element downstream of the start codon (downstream loop) pauses scanning long enough for Met-tRNA ${ }_{i}^{\text {Met }}$ to enter the initiation complex without an initiation factor ${ }^{20-22}$. In this case, ribosome stalling occurs when the downstream loop becomes trapped in a section of the $18 \mathrm{~S}$ ribosomal RNA (rRNA), locking the start codon in the $\mathrm{P}$ site ${ }^{23}$. This latter example shows how a virus can use a fairly small RNA element to overcome part of the host antiviral response.

Strategies to modify or prevent modification of the translation machinery. Some viruses also have the ability to alter the translation machinery in such a way as to influence the selection of an mRNA template in their favour or directly prevent the cell from limiting translation. For example, poxvirus kinase phosphorylates small ribosomal subunit proteins, which enhances the translation of viral mRNAs with conserved adenosine repeats in their $5^{\prime}$ UTRs $^{24}$. In addition, similar to some proteins, specific viral RNAs can prevent phosphorylation of eIF2 $\alpha$; examples include the adenovirus $V A^{25}$ and Epstein-Barr virus $E B E R^{26}$, which both act by binding and inhibiting the enzyme that phosphorylates eIF2 $\alpha$.

\section{Viral internal ribosome entry sites}

As outlined above, some viral RNAs mimic canonical initiation signals found in cellular mRNAs, but many have evolved mechanisms to bypass the need for these signals. In particular, cis-acting RNA elements called internal ribosome entry sites (IRESs) recruit the translation machinery through pathways independent of the $5^{\prime}$ end or cap. The advantages of using an IRES vary, but a common theme is that they allow viral protein synthesis when the canonical cap-dependent translation initiation mechanism is repressed. For example, some viruses that use IRESs encode proteases that cleave specific cellular eIFs; 


\section{UTRs \\ Portions of an mRNA outside \\ of its protein-coding region \\ These often contain sequences \\ or structures important for \\ the regulation of mRNA \\ translation, localization \\ or decay. \\ Kozak sequence \\ Sequence of RNA around a \\ translation start codon that \\ determines the "context \\ strength' of the AUG and thus \\ the degree to which that start \\ codon is used to begin \\ translation.}

\section{Ribosome profiling}

A next-generation

sequencing-based method to determine, at single-nucleotide resolution, the position of ribosomes on mRNAs on a transcriptome-wide scale.

Subgenomic RNA

(sgRNA). A viral RNA (generally transcribed from the viral genomic RNA) that is important for virus biology but does not contain the full viral genomic RNA sequence.

eIF2 a phosphorylation Eukaryotic initiation factor 2 (eIF2) delivers the initiator tRNA to the ribosome during initiation. Its $\alpha$-subunit can be phosphorylated as a response to various cellular stresses, including viral infection. This event in effect 'deactivates' the factor, which overall depresses translation that depends on elF2.

RNA stem-loop

An RNA secondary structure feature formed when a single strand of RNA folds back to base pair with itself, forming a loop at its apex. Also referred to as an RNA hairpin.

P site

The second tRNA binding site within the ribosome. After peptide bond formation. translocation moves the A-site tRNA (which is linked to the peptide chain) into the $\mathrm{P}$ site.

RNA pseudoknots

RNA structural elements formed when nucleotides in a stem-loop pair with regions outside the loop, often giving rise to a thermodynamically stable compact structure. There are many types of pseudoknots. this globally inhibits translation of most cellular mRNAs, but the virus can continue translation using its IRES. In other instances, the cellular antiviral response globally depresses cap-dependent translation through eIF2 $\alpha$ phosphorylation or eIF4E sequestration, but the IRES allows viral protein synthesis to continue. IRES structures are diverse, but many have substantial secondary and tertiary structure, and they mostly lie upstream of the ORF they control. Many of the IRESs have been divided into several mechanistic classes on the basis of how they recruit the ribosome, the eIFs that they require to function and similarities in their secondary structures ${ }^{27}$. Briefly, class 1 and 2 IRESs are generally larger and require more eIFs and protein cofactors than other classes in order to function. Class 3 IRESs bind directly to the ribosome but require only a few canonical eIFs for function. Class 4 IRESs form compact, well-defined folds that bind directly to the ribosome and function without using any eIFs. A second classification scheme has been proposed in which hepatitis A virus is the sole member of class 3 (REF. ${ }^{28}$ ). An interesting anti-correlation exists between the number of protein factors an IRES requires for translation initiation and the degree to which it forms a single well-defined conformation ${ }^{29}$. Below, we briefly describe key features of these IRES classes, starting with the simplest and best understood to the more complex and least understood. A more detailed description of the mechanisms and structures of these IRESs is found in REF. ${ }^{27}$.

Class 4 IRESs. Class 4 IRESs have thus far been identified exclusively in the family Dicistroviridae, of which the single-stranded RNA genomes contain two ORFs separated by an intergenic region (IGR). The IGR contains an IRES that controls translation of the downstream ORF, thus they are often referred to as the 'IGR IRESs'; they have been extensively functionally and structurally characterized since their discovery, providing insight into some basic aspects of ribosome function (reviewed in $\mathrm{REFS}^{30,31}$ ). There are two types of IGR IRESs, but all are $\sim 150-200$ nucleotides in length and are capable of initiating translation in a variety of cell types and organisms. These IRESs can even initiate translation in bacteria, although the mechanism appears to be inefficient and different than in eukaryotes ${ }^{32}$.

The molecular mechanism of these IRESs depends on its 3D structure, which allows them to initiate translation by co-opting the elongation cycle of translation. Early structural studies revealed that IGR IRESs fold into a compact structure containing three RNA pseudoknots in a two-domain architecture ${ }^{33-35}$. One pseudoknot domain (domain 3) partially mimics tRNA structure and the mRNA-tRNA codon-anticodon interaction ${ }^{36-38}$. To initiate translation, the folded IRES binds directly to the $40 \mathrm{~S}$ ribosomal subunit with high affinity and assembles an 80 S ribosome without using scanning, an AUG start codon, Met-tRNA ${ }_{i}^{\text {Met }}$ or any initiation factor (including eIF2 $)^{30,31}$. In fact, eIF2 $\alpha$ phosphorylation can increase translation initiation efficiency from these IRESs ${ }^{39}$, providing an elegant way for the virus to take advantage of this major cellular antiviral response mechanism. Within the assembled 80S ribosome, the IRES is placed between the two subunits with domain 3 in the A site of the ribosome, where it interacts with the ribosome in the same way as a codon-anticodon pair ${ }^{36}$ (FIG. 3a). One round of eEF2-catalysed 'pseudotranslocation' (so-called because it occurs without tRNA) moves this domain to the $P$ site, allowing charged tRNA delivery to the A site by eEF1A. A second round of eEF2-catalysed translocation moves this tRNA to the P site, enabling elongation. More recent studies have revealed details of the molecular movements occurring during this process $^{37,40-42}$; movement of the IRES through the space between the ribosomal subunits has been described as akin to that of an inchworm ${ }^{43}$.

Class 3 (hepatitis $C$ virus-like) IRESs. The bestknown class 3 IRES is from hepatitis $\mathrm{C}$ virus (HCV) (in the family Flaviviridae) (FIG. 3b); others have been found in viruses from the families Flaviviridae and Picornaviridae ${ }^{28,44}$. Unlike class 4 IRESs, class 3 IRESs have thus far been found only at the 5 ' end of viral RNAs, and they assume an extended architecture containing a variety of stem-loop structures that are organized around helical junctions and a pseudoknot (FIG. 3b). Interestingly, although the various class 3 IRESs share overall secondary structures with clear common patterns, there is also substantial sequence and structure variation that may provide for additional regulation or variation in function. This observation, and the fact that they appear in multiple virus families, suggests a useful versatility. It may not be immediately obvious why these viruses have evolved to use an IRES. One simple explanation is that class 3 IRES-containing viruses simply did not evolve the ability to cap the $5^{\prime}$ ends of their RNAs and thus were committed to developing a form of capindependent translation. However, a more compelling cause is that at least some class 3 IRESs can operate in both eIF2-dependent and eIF2-independent modes $^{45-48}$.

Extensive biochemical, genetic and structural studies have allowed development of mechanistic models for class 3 IRESs. Early structural studies consisted of NMR and X-ray crystallography applied to several isolated HCV IRES domains, which were combined with low-resolution cryo-electron microscopy (cryo-EM) reconstructions ${ }^{29}$. Most recently, high-resolution cryoEM structures of class 3 IRES-ribosome complexes have revealed the molecular details of the interactions underlying the structure-based mechanism ${ }^{49-51}$. Using the HCV IRES as an example, the structure of the IRES possesses several domains that have specific roles during IRES-driven translation initiation ${ }^{52}$. The IRES RNA directly binds to the $40 \mathrm{~S}$ ribosomal subunit and eIF3 using multiple contact points in domain III $^{53,54}$. Binding positions the AUG start codon within the decoding groove; thus, there is no scanning. Interestingly, in the IRES-40S-eIF3 complex, eIF3 is displaced from its normal binding position on the $40 \mathrm{~S}$ subunit $^{51}$; this displacement may be necessary for the IRES to access the $40 \mathrm{~S}$ subunit or it may be a functionally important remodelling step ${ }^{46}$. Domain II does not increase the affinity between the IRES and the $40 \mathrm{~S}$ subunit but makes specific contacts to the decoding groove of the ribosome, changes ribosome conformation and directs several mechanistically important events ${ }^{29,48,55-58}$. Domain II may 

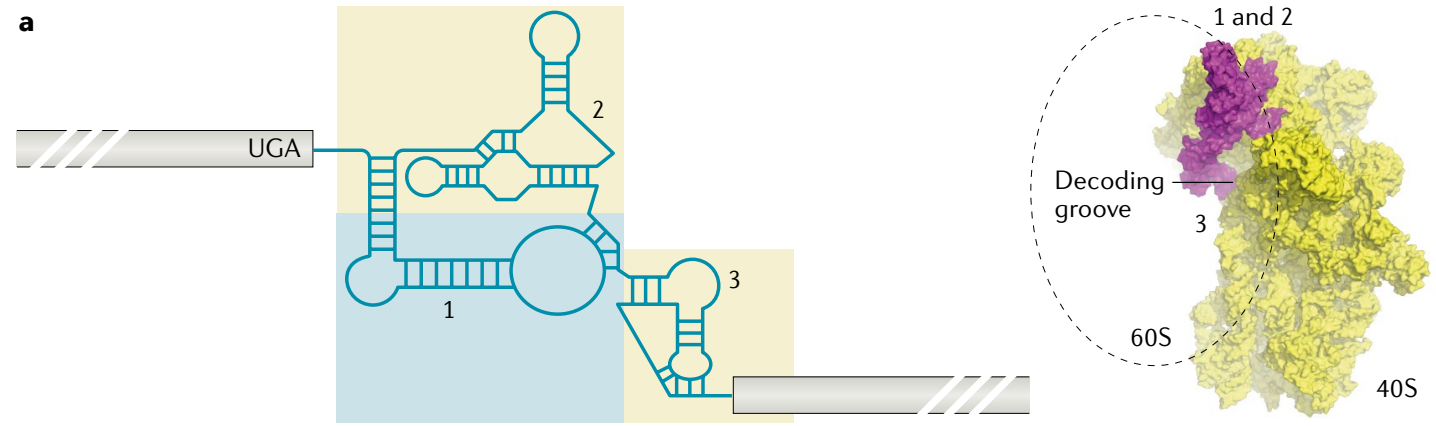

b
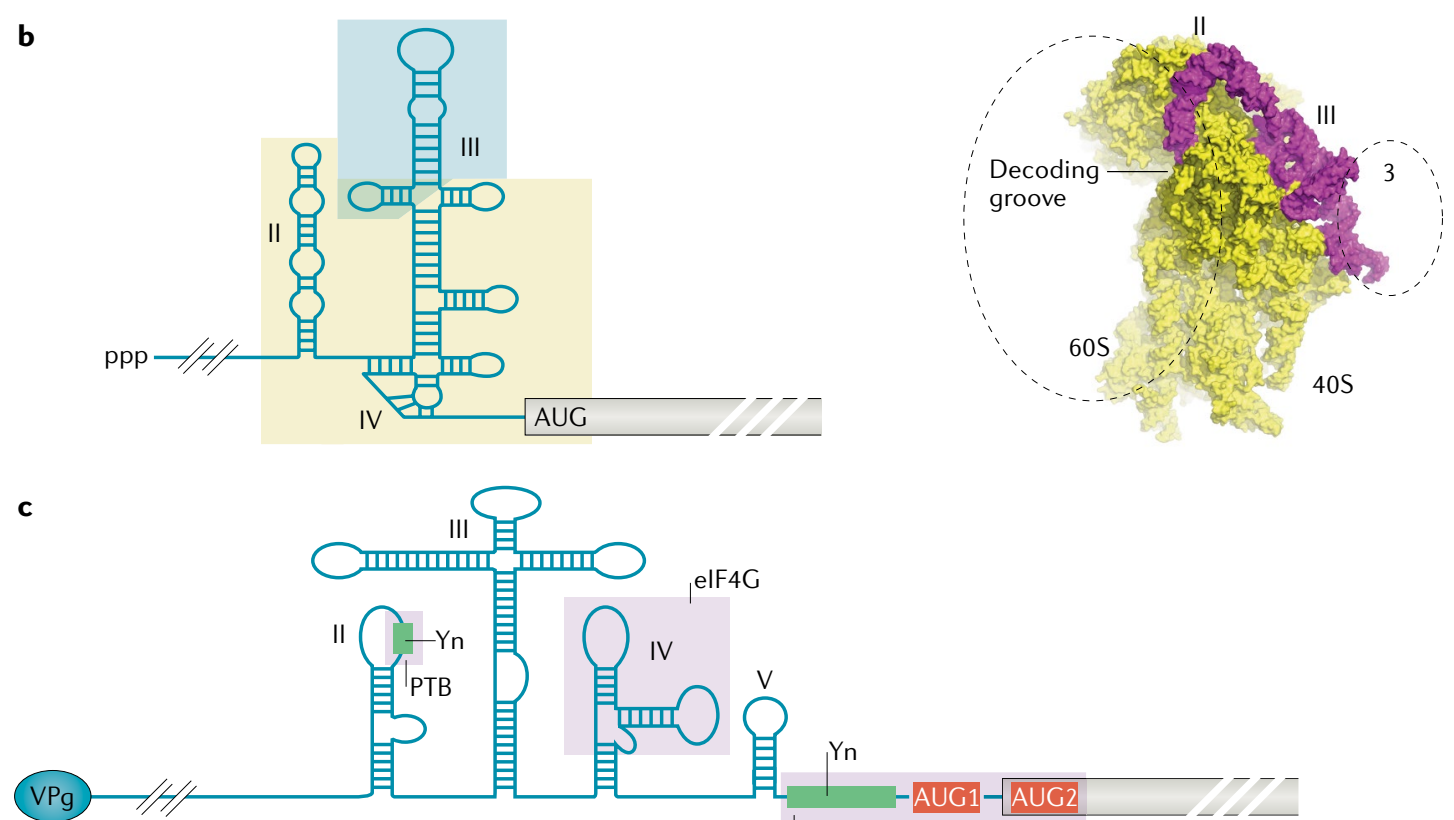

Yn
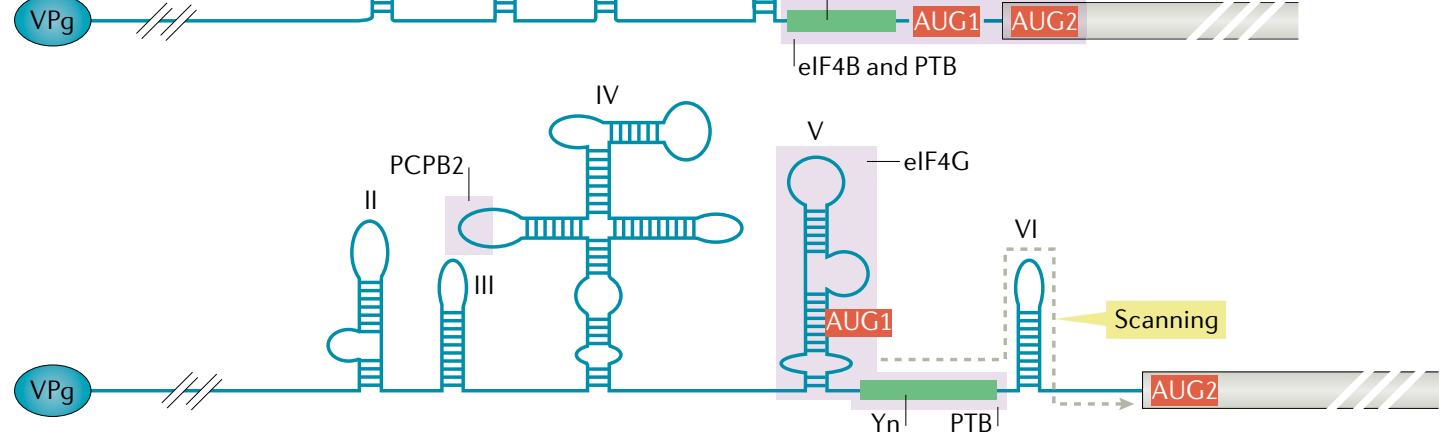

Fig. 3 Internal ribosome entry sites. a | Class 4 intergenic region internal ribosome entry sites (IRESs) are found between two viral ORFs. The three secondary structural domains are labelled. The yellow boxed area indicates the portion that interacts with the $40 \mathrm{~S}$ subunit, and the blue boxed area is the portion that interacts with the $60 \mathrm{~S}$ subunit. On the right is a cryo-electron microscopy (cryo-EM) reconstruction of the IRES bound to the 40S subunit (PDB $4 \mathrm{~V} 92)^{41}$, with the location of the domains labelled and the approximate location of the $60 \mathrm{~S}$ subunit shown. The $60 \mathrm{~S}$ subunit location is indicated, but that subunit has been removed to allow the domains of the IRES to be visualized. Domains 1 and 2 are labelled 1 and 2, as they form a single compact folded entity. $\mathbf{b}$ | Secondary structure cartoon of the hepatitis C virus IRES, representing the class 3 IRESs. The IRES is at the $5^{\prime}$ end of the viral genome, which starts with a triphosphate (ppp). Secondary structural domains are labelled, and the $40 \mathrm{~S}$ and $60 \mathrm{~S}$ subunit interaction sites are boxed in yellow and blue, respectively. At the right is a cryo-EM reconstruction of the IRES bound to the $40 \mathrm{~S}$ subunit $(\mathrm{PDB} 5 \mathrm{~A} 2 \mathrm{Q})^{49}$, with the location of the IRES RNA domains labelled and the approximate location of the 60S subunit shown; it has been removed to allow the full IRES to be seen. $\mathbf{c}$ C Class 1 and 2 IRESs are similar in organization and function but are not identical. Secondary structure cartoons of the encephalomyocarditis virus (class 2, top) and poliovirus (class 1, bottom) IRESs are shown, with secondary structure domains labelled. Both viral RNAs have a viral protein genome-linked (VPg) peptide on their $5^{\prime}$ end. Only the secondary structures necessary for IRES function are shown; upstream structures are omitted. The approximate binding sites for various eukaryotic initiation factors and IRES trans-acting factors are shown; additional details for related IRESs can be found in REFS ${ }^{27,44}$. In the class 2 IRESs (top), there are two closely spaced start codons at the 3' end of the IRES. For the class 1 IRESs (bottom), an upstream AUG codon (AUG1) is needed for ribosome entry, but then scanning leads to initiation at a downstream codon (AUG2). PCBP2, poly-C-binding protein 2; PTB, polypyrimidine tract-binding protein; Yn, polypyrimidine tract. 
Codon-anticodon

interaction

A stable interaction between an mRNA codon nucleotide triplet and the corresponding nucleotides in the anticodon stem-loop of a tRNA

A site

The first tRNA binding site within the ribosome. Here, mRNA codons are decoded by tRNAs during elongation.

\section{Translocation}

The simultaneous movement of mRNA and tRNA on the

ribosome after the formation of a new peptide bond (during elongation). The mRNA moves by three bases (one codon) accompanied by movement of the A-site tRNA to the P site and the P-site tRNA to the $\mathrm{E}$ site. The result is the next codon to be decoded in the A site, where it can be recognized by a tRNA.

\section{Decoding groove}

The part of the small ribosomal subunit that accommodates and orients mRNA codons as they are decoded by cognate tRNAs.

IRES trans-acting factors (ITAFs). Proteins that are not part of the canonical set of eukaryotic initiation factors but enhance or are required for translation initiation from a specific internal ribosome entry site.

Polypyrimidine tract A stretch of an RNA sequence containing a high percentage of cytosine and uracil bases.

GNRA tetraloops A type of RNA hairpin loop in which the loop contains four nucleotides of the pattern 'GNRA'; these are stable structures that often are involved in long-range RNA tertiary interactions. change position during the initiation process ${ }^{50}$, possibly acting as an important regulatory element.

Perhaps the most interesting step in class 3 IRES initiation is the delivery of Met-tRNA $\mathrm{i}_{i}^{\text {Met }}$ to the IRES-40SeIF3 complex, as this is when the ability to operate in an eIF2-dependent or independent mode comes into play. If eIF2 is available, Met-tRNA ${ }_{i}{ }^{\text {Met }}$ presumably is supplied by the factor. However, in the eIF2-independent mode, it has been proposed that Met-tRNA ${ }_{i}^{\text {Met }}$ could be delivered by alternative factors eIF2A or eIF2D ${ }^{59-61}$, or through the action of eIF5B alone ${ }^{47}$, or even through direct 'factorless' tRNA binding in the case of some class 3 IRESs $^{62}$. In addition, eIF1A appears to be particularly important for stabilizing tRNA binding in the eIF2-independent mode $^{46}$. Regardless of the pathway, once Met-tRNA $\mathrm{i}_{\mathrm{i}}^{\mathrm{Met}}$ is bound, $60 \mathrm{~S}$ subunit recruitment leads to $80 \mathrm{~S}$ ribosome formation and then elongation ${ }^{52}$.

Although a strong framework for understanding the class 3 IRESs exists, there are areas that require additional investigation. First, although we have presented the molecular mechanism of the HCV IRES translation initiation as a stepwise progression, there is uncertainty regarding the precise order of these recruitment events and how this might relate to the ability to use different tRNA binding modes. There is evidence that the HCV IRES binds pre-formed 40S subunit-containing preinitiation complexes at a specific step of ribosome recycling, then manipulates them to drive downstream steps of tRNA recruitment and $80 \mathrm{~S}$ ribosome formation $^{46}$. Second, although a limited set of canonical eIFs appear to be sufficient for translation on most class 3 IRESs tested, roles for some auxiliary factors have been proposed $^{63}$. Such factors combined with variable class 3 IRES structure may fine-tune function for certain cell types, for the specific needs of different viruses or for providing additional ways to respond to changing cellular conditions and antiviral responses.

Class 1 and 2 IRESs. Class 1 and 2 IRESs are found exclusively in picornaviruses and are similar to one another in that they are generally $\sim 450$ nucleotides long, are found in the 5' UTR of the viral RNAs, are unable to bind directly to the $40 \mathrm{~S}$ subunit and require almost the entire set of canonical translation initiation factors (excluding eIF4E) $)^{27,64}$. Both classes have complex secondary structures comprising multiple domains containing many stem-loops, internal loops, bulges and junctions (FIG. 3c). Both class 1 and 2 use IRES trans-acting factors (ITAFs) - protein factors that are not considered part of the canonical translation machinery but are functionally important to a specific IRES ${ }^{63}$. Viruses that use class 1 or 2 IRESs gain an advantage by depressing cap-dependent initiation while promoting IRES-driven translation ${ }^{5,44}$. Specifically, enteroviruses such as poliovirus cleave eIF4G, which decouples cap and factor binding, and the IRES then uses a cleaved fragment of eIF4G for translation initiation. Cardioviruses such as encephalomyocarditis virus (EMCV) cause the relocalization of eIF4E into the nucleus, which depresses cap-dependent translation, but class 1 IRES-dependent translation can continue. Both class 1 and 2 IRESs are at least partially refractory to eIF2 $\alpha$ phosphorylation during infection ${ }^{65}$.
For example, poliovirus may be able to operate in an eIF2-independent mode late during infection by using eIF5B ${ }^{66}$, suggesting that, similar to the class 3 and 4 IRESs, they have evolved strategies to bypass canonical Met-tRNA ${ }_{i}^{\text {Met }}$ delivery. Despite these similarities, class 1 and 2 IRESs are not identical in terms of secondary structure and mechanism, and there are variations within each class. To present some overarching mechanistic concepts, we use the poliovirus and EMCV IRESs as prototypes for classes 1 and 2, respectively, and direct the reader to focused reviews for further information on other IRESs ${ }^{27,44,64}$

The general model that has emerged from biochemical and genetic experiments is that class 1 and 2 IRESs are flexible scaffolds to which ITAF binding facilitates eIF binding, leading to recruitment of the ribosome. In the case of the class II EMCV IRES, polypyrimidine tractbinding protein (PTB) is an important ITAF that simultaneously binds to polypyrimidine tracts (Yn) near the $5^{\prime}$ (domain II) and 3' ends of the IRES (just upstream of the translation start site), altering the overall conformation of the IRES ${ }^{67,68}$ (FIC. 3c). The class 1 poliovirus IRES also uses $\mathrm{PTB}$ as an $\mathrm{ITAF}^{69}$ and poly-C-binding protein 2 (PCBP2), which binds to a cytosine-rich stretch in the large central domain IV of the poliovirus IRES ${ }^{70}$ (FIG. 3c). PTB and PCBP2 are not the only ITAFs that have been identified, and there is variation across the various members of the class 1 and 2 IRESs $^{44}$. In addition to ITAF binding, long-range RNA-RNA interactions involving GNRA tetraloops are proposed to further organize the active conformation of both class 1 and 2 IRESs $^{71-73}$.

The ITAF-assisted conformation of the class 1 and 2 IRESs is the platform for recruiting eIFs: in the poliovirus IRES, eIF4G and eIF4A bind to domain $\mathrm{V}^{70}$, whereas in the EMCV IRES they bind to domain $\mathrm{IV}^{74}$. It is worth noting that in viral infections in which eIF4G is cleaved by viral proteases, the amino-terminal fragment of eIF4G that binds eIF4E is lost, whereas the carboxy-terminal fragment that interacts with eIF3 interacts directly with the IRES RNA. EMCV IRES domain V also binds other factors, including eIF $4 \mathrm{~B}^{75}$. Binding of eIFs to the class 1 and 2 IRESs then leads to the recruitment of the $43 \mathrm{~S}$ complex. However, the class 1 and 2 IRESs differ in the use of start codons for initiation ${ }^{44}$. For the class 2 EMCV IRES, translation initiates without scanning at the second of two closely spaced AUG codons ${ }^{76}$. However, other class 2 IRESs appear to use both AUG start codons, suggesting that scanning occurs ${ }^{77}$. During translation from the class 1 poliovirus IRES, the ribosome is initially recruited to an upstream 'cryptic' AUG codon, and it then scans through domain VI to reach the AUG start codon ${ }^{78,79}$.

Despite a good mechanistic and biochemical framework for understanding class 1 and 2 IRESs, their large and extended architectures and the complexity of the associated translation preinitiation complexes have made structural studies difficult. Isolated domains of IRESs have been investigated using $\mathrm{NMR}^{80,81}$, and smallangle X-ray scattering has been used to determine the global shape of part of EMCV IRES domain IV bound to the HEAT1 domain of eIF4G ${ }^{81}$. However, to date, the structures of assembled class 1 or 2 IRES-ribosome-eIFITAF complexes are unsolved. This gap in knowledge 
a

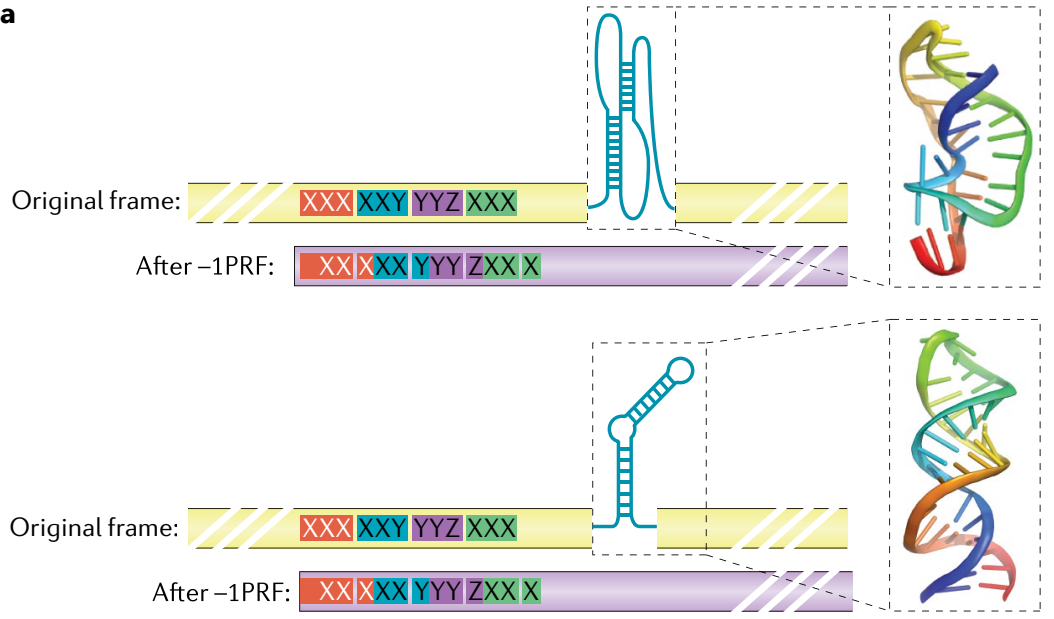

b

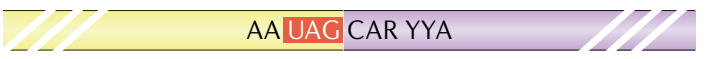

c
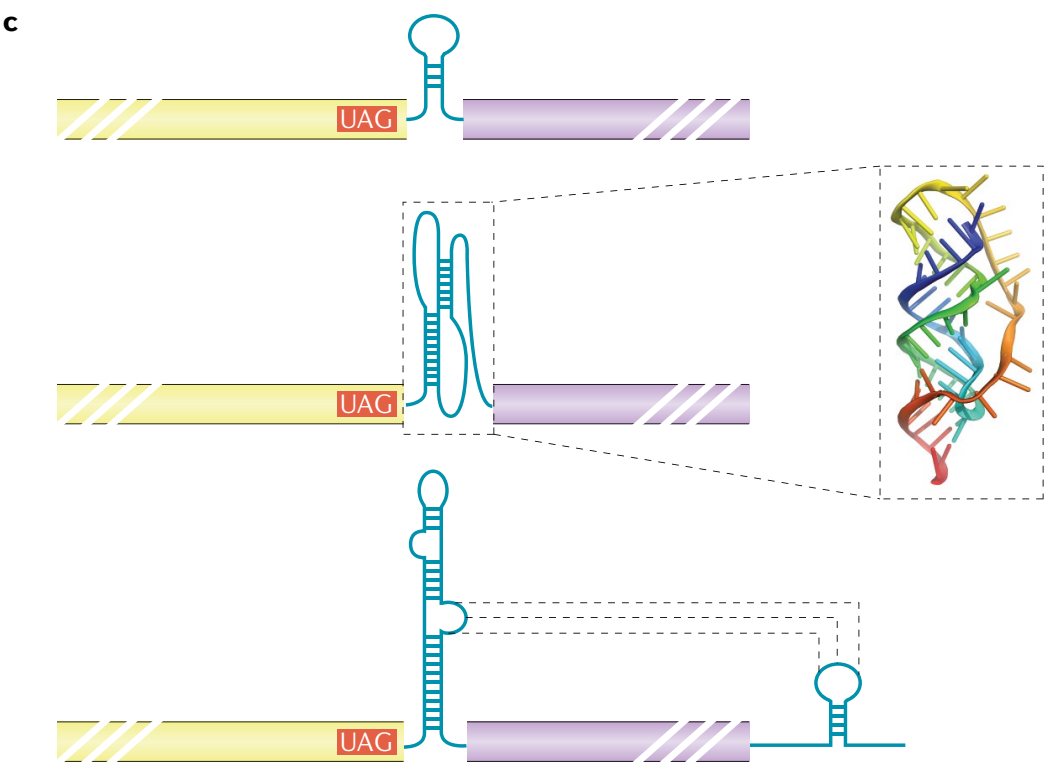

d

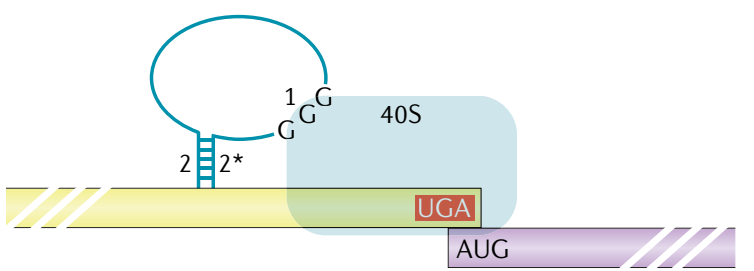

G-quadruplex structures Stable RNA motifs in which guanine residues form tetrads through extensive hydrogen bonding; two or more tetrad structures may base stack to form higher-order quadruplexes. limits our ability to fully understand how these complex assemblies are constructed, differences when compared with canonical initiation and the dynamic conformational changes that take place. We expect advances in cryo-EM coupled with other structural methods to help address these unknowns.

Other viral IRESs. In addition to those described above, other IRESs have less well-understood mechanisms and structures and therefore cannot be easily classified. For example, the Halastavi árva virus 5' UTR IRES operates with most canonical eIFs but requires retrograde
Fig. 4 | RNA elements within the coding region. Specific folded RNA elements within a coding region can affect translation and lead to decoding of an alternative or extended frame. a | Programmed ribosomal frameshifting can be induced by structures that stall the ribosome and are coupled to slippery sequences. If encountered, RNA in the decoding groove can then shift into a different frame (in this example, a shift backwards of one nucleotide, in other words, a -1 programmed ribosomal frameshift (-1PRF)). If this occurs, translation continues but in a different frame (purple) than the original frame (yellow). Frameshifting can occur as a result of special pseudoknots (above) or stem-loops (below). NMR structures of a frameshifting pseudoknot from mouse mammary tumour virus (PDB 1RNK) ${ }^{160}$ or a hairpin from HIV-1 (PDB 1ZC5) ${ }^{92}$ are shown. b | Stop codon readthrough can occur through a variety of RNA-based mechanisms; when it occurs, the sequence downstream (purple) is translated. This simple case relies only on RNA sequence. Some tobamoviruses contain a stop codon within a UAG-CARYYA motif ( $R$ is a purine and $Y$ is a pyrimidine) that can induce readthrough at low frequencies. c | Readthrough can be driven by structured RNA. A simple stem-loop (top). A pseudoknot from murine leukaemia gammaretrovirus and its NMR structure to the right (PDB 2LC8) ${ }^{113}$ (middle). The carnation Italian ringspot Tombusvirus readthrough signal involves longrange interactions (bottom). $\mathbf{d}$ | Termination upstream ribosome-binding sites (TURBSs) exist in some caliciviruses. They contain a stem (motifs 2 and $2^{\star}$ ) with an extended loop (motif 1 ) that binds the ribosome on a terminating message to stimulate reinitiation on a downstream ORF (purple).

scanning $^{82}$, precluding easy assignment to any aforementioned class. Other IRESs are more challenging to classify. For example, the leader sequence of HIV-1 RNAs alone can stimulate translation in a cell-type-specific manner ${ }^{83}$, but different HIV-1 transcripts contain different IRES structures and splice site variations ${ }^{84}$, and the viral transcripts are capped. In HIV-1 and other retroviruses, the contributions of IRES-dependent and cap-dependent translation during infection remain the subject of debate ${ }^{85}$. Overall, the diversity of structures and mechanisms used by IRESs is greater than initially anticipated, and future characterization of these RNAs must include focused studies of many different examples to discover both idiosyncratic features of individual IRESs and common principles.

\section{Elongation and termination}

Initiation is the most regulated phase of translation, but regulation also occurs during elongation or termination through RNA-based signals within an ORF (FIG. 4). Viruses that depend on RNA elements that are encoded within ORFs must simultaneously maintain coding capacity and functional structures. Thermodynamically stable RNA elements within coding regions can alter translation efficiency. Viral mRNAs use this phenomenon to slow translation; for example, the Epstein-Barr virus EBNA1 mRNA contains regions that can form very stable G-quadruplex structures ${ }^{86}$. In this section, we discuss three other examples: RNA structure-dependent programmed ribosomal frameshifting (PRF), stop codon readthrough and termination-coupled reinitiation. 
Programmed ribosomal frameshifting signals. PRF occurs when a specific RNA element causes an elongating ribosome to pause and the mRNA-tRNA codonanticodon interactions break and then reform in a different reading frame; often the shift is one nucleotide backwards, leading to ' $-1 P R F$ '87,88. As viruses have limited coding capacities, many viral genomes encode overlapping ORFs and use PRF to double or triple the coding capacity of a single RNA template (FIG. 4a). The percentage of ribosomes that undergo frameshifting is generally only a small percentage, but it can reach $40 \%$ for some viral -1PRF signals ${ }^{89}$. These RNA signals also have evolved to achieve a specific ratio of protein products.

PRF signalling structured RNA elements have been documented in bacterial, yeast, plant and mammalian systems and consist of two types. The first is a pseudoknot located six to eight nucleotides downstream of a 'slippery sequence ${ }^{88}$. These pseudoknots often control the expression of the gag-pro or gag-pol genes of retroviruses, regulating the relative expression of structural and non-structural proteins. Interestingly, PRF in severe acute respiratory syndrome (SARS) coronavirus infection may involve trans RNA-RNA interactions ${ }^{90}$. The second type of structure is a thermodynamically stable stem-loop. Examples are found in other members of the family Retroviridae such as HIV-1, HIV-2 and simian immunodeficiency virus ${ }^{91-93}$ (FIG. 4a). For stemloop-directed frameshifting, stability of the stem is of primary importance, but adjacent structures and longrange interactions with other RNA elements can further modulate frameshifting. An interesting example is the pea enation mosaic virus (PEMV) recoding stimulatory element; RNA secondary structure elements upstream and downstream of the frameshift site modulate the frequency of frameshifting, which occurs just upstream of a termination codon ${ }^{94}$. Interestingly, dynamic rearrangement between a pseudoknot and a tandem stemloop conformation in a -1PRF signal in West Nile virus RNA seems important for frameshifting ${ }^{95}$, highlighting the complexity of the molecular motions that govern this process.

The mechanism by which specific RNA elements stimulate frameshifting at a slippery sequence remains an area of active investigation. Thermostability of the RNA fold alone does not dictate frameshifting efficiency $^{96}$, and mechanisms may differ between individual frameshifting signals. In some cases, frameshifting correlates with stability of ribosome-adjacent base pairing $^{97}$ and metastable or non-canonical conformations on an elongating ribosome $e^{87,98}$. The resolution of paused ribosomes into either the 0 or -1 frame is influenced by the dynamics of the PRF structure ${ }^{95}$ and the inherent helicase activity of ribosomes ${ }^{99}$. Viral frameshifting can also be stimulated by viral and cellular protein factors that bind viral RNA adjacent to the slippery site and act in place of, or in concert with, higher-order RNA folding. For example, porcine reproductive and respiratory syndrome virus utilizes a complex of its Nsp1 $\beta$ replicase subunit and PCBP that associates with a sequence downstream of the slippery site and directs either -2 or -1 frameshifting ${ }^{100-102}$. Additionally, the cardioviruses EMCV and Theiler's murine encephalomyelitis virus contain atypically spaced stem-loops proximal to frameshifting sites that seem to cooperate with the viral 2A protein to facilitate high-efficiency frameshifting ( 70-82\% frameshifting $)^{103-105}$.

Stop codon readthrough. Viruses can increase coding capacity by the ribosomal readthrough of stop codons, resulting in extended protein isoforms. Signals near the stop codon may promote recognition by a suppressor tRNA rather than by a termination factor protein, dependent primarily on the RNA sequence immediately adjacent to the stop codon ${ }^{106-109}$. Tobacco mosaic virus and other plant viruses use this method to make extended coat protein isoforms ${ }^{110}$. Another signal that can cause readthrough is an RNA element just 3 ' to the stop codon, including a stem-loop or pseudoknot (FIG. 4C). A stem-loop has been computationally predicted to exist in some alphaviruses and plant viruses within the family Virgaviridae ${ }^{111}$ and experimentally shown in Colorado tick fever virus ${ }^{112}$. Pseudoknots are also implicated in translational readthrough in murine leukaemia gammaretrovirus infection ${ }^{113,114}$. Readthrough can be promoted by a long-range cis interaction involving RNA near the stop codon (for example, in some members of the Tombusviridae and Luteoviridae families ${ }^{15}$ ) (FIG. 4 c, bottom). The precise molecular mechanisms of readthrough in viral RNAs remain poorly defined. Recent studies of readthrough in turnip crinkle virus (TCV) infection suggest that these RNA elements can adopt multiple conformations, further illustrating the dynamic and complex nature of viral recoding elements ${ }^{116}$. Lacking detailed knowledge of the molecular mechanisms, it is tempting to hypothesize a mechanism in which these RNA elements slow translation termination long enough to favour the recruitment of low-abundance suppressor tRNAs ${ }^{117}$.

Termination-dependent reinitiation. Viruses can manipulate translation by interrupting the recycling of a terminated ribosome in favour of reinitiation of an adjacent viral ORF; this differs from readthrough in that the synthesis of the first protein terminates, and then the ribosome reinitiates at a site proximal to the termination site (either upstream or downstream) to produce a second protein. A well-characterized example of reinitiation, used by feline calicivirus, is directed by a structured RNA element called the termination upstream ribosome-binding site (TURBS) that lies within the last 40-80 nucleotides of the upstream ORF (FIG. 4d). This type of reinitiation was originally suspected to be $-1 P R F$ and exists within other Caliciviridae family members (including human and bovine noroviruses) and haemorrhagic viruses such as rabbit haemorrhagic disease virus ${ }^{118-120}$. The TURBS contains a sequence that forms complementary interactions with the apical loop of helix 26 of $18 \mathrm{~S}$ rRNA. Viral RNA-rRNA base pairing is sufficient to retain the $40 \mathrm{~S}$ subunit for a time after termination $^{121}$, then the $40 \mathrm{~S}$ subunit can move to the second ORF start site a short distance away; subsequent reinitiation appears to be more streamlined than normal initiation $^{122}$. Notably, the ribosomal binding site of the 

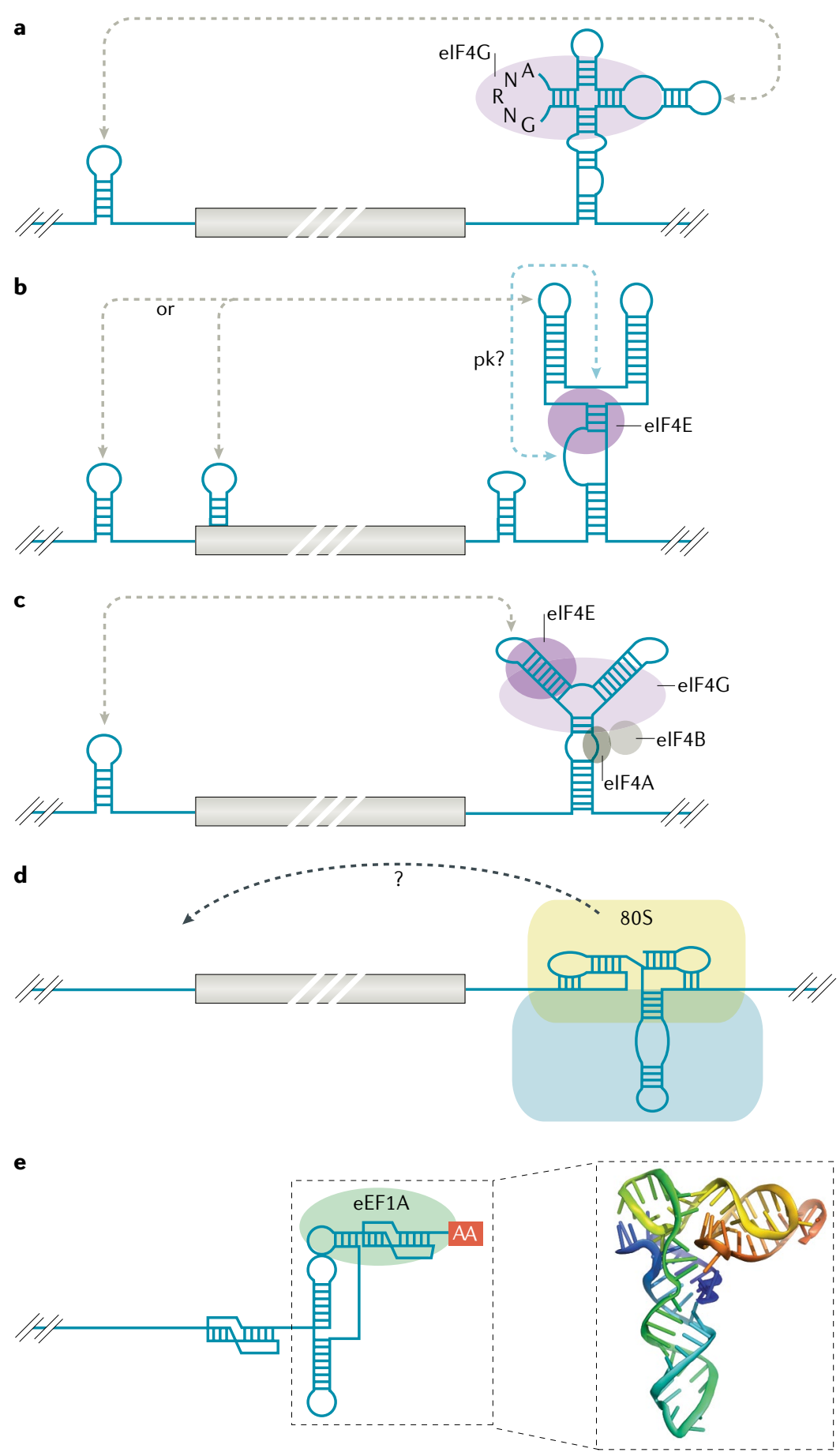

Fig. 5 | Translation enhancers in the $3^{\prime}$ UTR or at the $3^{\prime}$ end. a $\mid$ A class of $3^{\prime}$ capindependent translation elements ( 3 '-CITEs) called BTEs (barley yellow dwarf virus translation elements) adopt extended RNA architectures in the 3' UTR, interacting with eukaryotic initiation factor 4G (elF4G) and a stem-loop in the $5^{\prime}$ UTR to facilitate translation. $\mathbf{b}$ | PTEs (panicum mosaic virus-like translation enhancers) such as the one from saguaro cactus virus contain motifs that may pseudoknot (indicated by pk?) to form structures that recruit elF4 $\mathrm{E}^{161}$ and participate in long-range interactions with the sequence in either the $5^{\prime}$ UTR or the $5^{\prime}$ coding region ${ }^{161}$. Other PTEs may interact with sequence in the $5^{\prime}$ coding region. $\mathrm{c}$ | I-shaped structures or $\mathrm{Y}$-shaped structures (YSSs) recruit some component of the cap-binding complex and interact with sequences in the $5^{\prime}$ end of the mRNA (a YSS is shown). $\mathbf{d} \mid$ T-shaped structure (TSS)-type 3'-CITEs are proposed to bind directly to ribosomal subunits. elTLSs (tRNA-like structures) are aminoacylated (AA, red), bound by eEF1A and/or interact with the ribosome. Crystal structure of the turnip yellow mosaic virus TLS is shown here (PDB 4P5J) $)^{156}$.
TURBS is remarkably similar to sequences in the class 3 IRESs that are needed for $40 \mathrm{~S}$ subunit recruitment, suggesting either an evolutionary link between these RNA elements (and thus between IRES-driven initiation and reinitiation) or a convergent mechanistic solution to the problem of recruiting and manipulating the 40 S subunit.

\section{Controlling translation from the $3^{\prime}$ end}

Some viral RNAs contain RNA elements near the $3^{\prime}$ end that control or manipulate the translation machinery. A variety of such elements are found in plant viruses; we will focus on them as interesting and important examples. In most cases, the mechanism of translational control involves long-range interactions between the $5^{\prime}$ and $3^{\prime}$ ends of the viral RNA using interactions and signals differing from canonical cap-poly(A) tail $5^{\prime}$ to 3' communication.

3' cap-independent translation elements. 3 ' capindependent translation elements ( $3^{\prime}$-CITEs) are structurally diverse RNA elements in the 3' UTRs of many RNA plant viruses that allow translation of the upstream sequences by recruiting translation components (eIFs or ribosomal subunits) to the $3^{\prime}$ UTR, but then translation initiates at the $5^{\prime}$ end owing to $5^{\prime}$ to $3^{\prime}$ communication $^{123-126}$. Seven $3^{\prime}$-CITE structural classes have been identified ${ }^{125}$. Although naturally found in the $3^{\prime}$ UTR, 3 '-CITEs have been shown to function when placed in the $5^{\prime} \mathrm{UTR}^{127}$, and $3^{\prime}$-CITEs from one virus have been shown to function in other viruses, demonstrating that they are portable elements. However, unlike IRESs (which can drive translation initiation independent of the $5^{\prime}$ end), the $5^{\prime}$ end is needed for the function of some $3^{\prime}$-CITEs even if the cap is not ${ }^{128-130} \cdot 3^{\prime}$-CITEs could provide several advantages to the virus. First, they could allow successful competition with cellular mRNAs for translation components, as the affinity of many 3 '-CITEs for their target eIFs is high (dissociation constants in the mid-nanomolar range $)^{131,132}$. In addition, $3^{\prime}$-CITEs could capture ribosomes terminating at the $3^{\prime}$ end and deliver them to the 5 ' end. This mechanism could prevent any hindrance between the replication and translation machineries if they were operating on the same viral RNA, or it could regulate the rate of translation of different subgenomic viral RNAs with different $5^{\prime}$ UTRs $^{133}$. Several excellent recent reviews describe the diversity of 3 '-CITE structure and function ${ }^{123-126}$; therefore, we briefly provide representative examples to illustrate key concepts.

Most known 3'-CITEs function by directly binding components of the cap-binding elF4F complex; for example, the highly efficient barley yellow dwarf virus translation element (BTE) found in some members of the family Tombusviridae ${ }^{134-137}$ (FIG. 5a). The BTE contains a conserved stem-loop structure that directly binds eIF4G, aided by other factors, in a way that still allows eIF4G to bind poly(A) binding protein (PABP) and eIF4E $\mathrm{E}^{138-140}$. Base pairing between a sequence in the $3^{\prime}$-CITE and a complementary sequence in the $5^{\prime}$ UTR brings the bound factor or factors to the $5^{\prime}$ end where they can drive translation initiation ${ }^{128,129,137}$. Other $3^{\prime}$-CITEs use specific RNA sequences and structures to directly bind $\mathrm{eIF}^{1} \mathrm{E}^{141-144}$ (FIG. 5b) or the intact eIF4F complex ${ }^{126}$ (FIG. 5c). 


\section{elF4F complex}

A complex of three eukaryotic initiation factors (elFs) (elF4E, elF4G and elF4A) responsible for recognizing the $5^{\prime}$ capped end of an mRNA and recruiting a ribosome for subsequent translation.

T-shaped structures (TSSs). Sites of 3' capindependent translation elements that are proposed to form a secondary structure that looks like a ' $T$ '.

Kissing-loop interactions Long-distance base pairing between the loop bases of two RNA stem-loops. This interaction can occur between elements very distal in sequence
For example, the panicum mosaic virus-like translation enhancers (PTEs) are a class of 3'-CITEs that bind directly to eIF4E using a folded RNA element coupled with long-range interactions to complementary sequences in either the $5^{\prime}$ UTR or within an upstream coding region ${ }^{126,144}$.

Most types of 3'-CITEs directly bind eIFs; however, others directly bind to the ribosome itself. For example, the T-shaped structures (TSSs) found in TCV and cardamine chlorotic fleck virus RNAs directly interact with $80 \mathrm{~S}$ ribosomes or $60 \mathrm{~S}$ subunits ${ }^{145,146}$ (FIG. $5 \mathrm{~d}$ ), and they have been proposed to form folded structures akin to tRNAs. Unlike most 3'-CITEs, TSSs lack identified sequences that base pair with the $5^{\prime}$ end (with the exception of the kissing-loop TSS, so named because it base pairs long distance with a hairpin-loop structure); the 'bridge' between the two ends is thought to occur through the $40 \mathrm{~S}$ subunit association with the $5^{\prime}$ end $^{147}$. Interestingly, some viruses use more than one type of 3'-CITE cooperatively. For example, PEMV2 possesses an eIF-binding PTE that lacks the ability to pair to 5 ' sequences, a $60 \mathrm{~S}$ subunit and $80 \mathrm{~S}$ ribosome-binding TSS (used only by the sgRNA) ${ }^{148}$ and a kissing-loop TSS that binds both ribosome subunits and forms longdistance kissing-loop interactions with a hairpin in the coding region ${ }^{149,150}$. In addition, new types of $3^{\prime}$-CITEs and combinations of 3 '-CITEs continue to be discovered. The most recently identified type comes from Cucurbit aphid-borne yellows virus (CABYV)-Xinjiang. Only 55 nucleotides long, the CABYV-Xinjiang-like translation element (CXTE) functions in eIF4E-depleted lysate and is enhanced by the viral 5' UTR; however, the detailed molecular mechanisms remain unknown ${ }^{125}$. Interestingly, the melon necrotic spot virus appears to have acquired a CXTE (from CABYV) in addition to an I-shaped structure (a type of 3'-CITE named for its extended secondary structure) ${ }^{125}$. This example illustrates how 3'-CITEs can transfer between viruses and how it is likely that additional types of $3^{\prime}$-CITEs, and combinations of 3'-CITEs, are awaiting discovery.

Despite the importance, widespread distribution and diversity of 3'-CITEs, to date there is limited information about their 3D structures. Structural predictions of the PTEs from PMV and PEMV2 in both the apo form and eIF4E-bound form have been constructed ${ }^{144}$, but there are no experimentally determined structures. Also, molecular models of the TSS from TCV and the kissing-loop TSS from PEMV2 have been constructed that predict structural characteristics akin to tRNAs ${ }^{124}$, and the structure of the TCV TSS has been studied by NMR and small-angle X-ray scattering ${ }^{151}$. However, to date there are no high-resolution structures of other diverse 3 '-CITEs in isolation or bound to their translation machinery targets. In addition, conformational changes and dynamics within these complexes are important ${ }^{152}$; recent quantitative biophysical and structural studies of the TCV TSS revealed how the TSS is disassembled through viral RNA-dependent RNA polymerase binding, a requirement for replication ${ }^{153}$. However, more exploration is needed to understand the conformational dynamics underlying 3'-CITE binding to their targets and their functions.
tRNA-like structures. The extreme $3^{\prime}$ terminus of Tymovirus and Tobamovirus plant viruses contains elements that recruit specific host aminoacyl tRNA synthetases to aminoacylate the $3^{\prime}$ end of the viral RNA, an event that promotes diverse viral processes including stabilizing the viral RNA and enhancing translation from a capped $5^{\prime}$ end by a mechanism that remains unknown $^{154}$. These 'tRNA-like structures' (TLSs) exist in three types with distinct secondary structures and tertiary folds ${ }^{154}$, charged with either valine, histidine or tyrosine. Aminoacylated TLSs also bind eEF1A ${ }^{155}$, and the turnip yellow mosaic virus (TYMV) TLS has a high affinity for ribosomes ${ }^{156}$. Biophysical and biochemical studies have informed the development of models of different TLS types, but only the structure of the unbound TLS RNA from TYMV has been experimentally solved to high resolution ${ }^{156}$ (FIG. 5e). This structure reveals a global tRNA-like fold but with marked differences compared with tRNAs that help explain its multifunctionality. In the case of TYMV TLS, there is evidence that the tRNA-like fold forms tertiary interactions with an adjacent upstream pseudoknot domain (UPD) and could serve as a structural switch to control events during infection ${ }^{157}$. However, the molecular details of how aminoacylation and factor binding to the TLS at the $3^{\prime}$ end enhance translation from the $5^{\prime}$ end is still unclear. One study concluded that the TYMV TLS can deliver a valine as the first amino acid of viral proteins ${ }^{158}$; other studies have challenged this finding ${ }^{159}$. It could be that eEF1A-bound TYMV TLS interacts with either the ribosome or other components of the translation machinery and recruits them to the viral RNA, but this has yet to be definitively shown, and there is no clear mechanism of $5^{\prime}$ to $3^{\prime}$ communication.

\section{Summary and future directions}

In this Review, we have presented an overview of the many types of RNA elements that manipulate the eukaryotic translation machinery at all phases of the protein synthesis process: initiation, elongation, termination and recycling. Using illustrative examples, we show how these RNA elements are abundant and structurally and mechanistically diverse and how they provide viruses with sophisticated ways to exploit the translation machinery or overcome antiviral defences. Studying these RNA elements not only provides insight into virus replication mechanisms and new targets for therapeutic intervention or agricultural control but also increases our understanding of the fundamental mechanisms of translation.

As we have explored diverse types of RNAs, we have highlighted some of the major unknowns. For a given functional RNA, we may know the sequence, have a putative secondary structural model, have identified some interacting proteins and know the translation phases involved, but for most of these RNAs, there is still much to be learned. For example, for most, we do not know the 3D structures of the RNA elements, the details of how they interact with their targets and the consequences of that interaction. For example, when a viral RNA binds to an eIF or to the ribosome, where does it bind and how does this alter the structure of 
the target to alter function in a way that promotes viral replication? Likewise, there is a need to understand the dynamics of these interactions and processes in many ways: how do the interactions between viral RNAs and their targets change as cellular conditions change? Does cellular localization affect these processes? Moreover, translation is intimately connected to other cellular processes such as RNA decay, raising the question of how these viral mechanisms are affected by or function within a global context. We predict that some of the next important advances will be comprehensive descriptions of the detailed structures of viral RNAs in complex with their targets, an understanding of how these interactions lead to manipulation of the translational machinery, how conditions change during the course of the viral infection, how these events are coordinated with other viral processes and how this relates to pathogenesis.

Answering these questions will require contributions from many fields, including virology, structural biology, biochemistry and cell biology. Excitingly, new tools are emerging that can help address these questions. For example, advances in structural methods such as cryoEM will allow the visualization of large complexes that include viral RNAs and the translation machinery, which is particularly useful for studies of IRESs and 3'-CITEs. Likewise, super-resolution microscopy and methods such as time-resolved fluorescence in situ hybridization (FISH) should provide insight into the changing localization and composition of viral RNA-protein complexes in cells. Methods such as ribosome profiling and in-cell chemical probing of RNA will allow the characterization of RNA structures and translational status during the course of viral infection. The next advances will not come from a single approach but from an integration of these emerging technologies with classical virology and biochemistry.

\section{Published online 4 December 2018}

1. Hinnebusch, A. G. \& Lorsch, J. R. The mechanism of eukaryotic translation initiation: new insights and challenges. Cold Spring Harb. Perspect. Biol. 4 a011544 (2012).

2. Dever, T. E. \& Green, R. The elongation, termination, and recycling phases of translation in eukaryotes. Cold Spring Harb. Perspect. Biol. 4, a013706 (2012)

3. Nurenberg, E. \& Tampe, R. Tying up loose ends: ribosome recycling in eukaryotes and archaea. Trends Biochem. Sci. 38, 64-74 (2013).

4. Spriggs, K. A., Bushell, M. \& Willis, A. E. Translational regulation of gene expression during conditions of cell stress. Mol. Cell 40, 228-237 (2010).

5. Walsh, D., Mathews, M. B. \& Mohr, I. Tinkering with translation: protein synthesis in virus-infected cells. Cold Spring Harb. Perspect. Biol. 5, a012351 (2013).

6. Walsh, D. \& Mohr, I. Viral subversion of the host protein synthesis machinery. Nat. Rev. Microbiol. 9 , 860-875 (2011).

7. Jan, E., Mohr, I. \& Walsh, D. A. Cap-to-tail guide to mRNA translation strategies in virus-infected cells. Annu. Rev. Virol. 3, 283-307 (2016).

8. Ramanathan, A., Robb, G. B. \& Chan, S. H. mRNA capping: biological functions and applications. Nucleic Acids Res. 44, 7511-7526 (2016).

9. Decroly, E., Ferron, F., Lescar, J. \& Canard, B. Conventional and unconventional mechanisms for capping viral mRNA. Nat. Rev. Microb. 10, 51-65 (2011).

10. Bouloy, M., Plotch, S. J. \& Krug, R. M. Globin mRNAs are primers for the transcription of influenza viral RNA in vitro. Proc. Natl Acad. Sci. USA 75, 4886-4890 (1978).

This study reports that the capped ends of endogenous mRNAs are 'hijacked' to allow influenza virus transcription and translation.

11. Fujimura, T. \& Esteban, R. Cap snatching in yeast L-BC double-stranded RNA totivirus. J. Biol. Chem. 288, 23716-23724 (2013).

12. Fujimura, T. \& Esteban, R. Cap-snatching mechanism in yeast L-A double-stranded RNA virus. Proc. Natl Acad. Sci. USA 108, 17667-17671 (2011).

13. Dong, H. et al. Flavivirus RNA methylation. J. Gen Virol. 95, 763-778 (2014).

14. Hyde, J. L. \& Diamond, M. S. Innate immune restriction and antagonism of viral RNA lacking 2 '-O methylation. Virology 479-480, 66-74 (2015).

15. Kozak, M. Point mutations define a sequence flanking the AUG initiator codon that modulates translation by eukaryotic ribosomes. Cell 44, 283-292 (1986). This study provides important insight into the details of translation start codon selection, showing that translation initiation is not as simple as finding the first AUG codon.

16. Vera-Otarola, J. et al. The Andes hantavirus NSs protein is expressed from the viral small mRNA by a leaky scanning mechanism. J. Virol. 86, 2176-2187 (2011).
17. Andreev, D. E. et al. Insights into the mechanisms of eukaryotic translation gained with ribosome profiling. Nucleic Acids Res. 45, 513-526 (2017). This article presents a review on the power of ribosome profiling to provide insight into various translation mechanisms.

18. Turina, M., Desvoyes, B. \& Scholthof, K. B. A gene cluster encoded by panicum mosaic virus is associated with virus movement. Virology 266, 120-128 (1999).

19. Haimov, O., Sinvani, H. \& Dikstein, R. Cap-dependent, scanning-free translation initiation mechanisms. Biochim. Biophys. Acta 1849, 1313-1318 (2015)

20. Ventoso, I. Adaptive changes in alphavirus mRNA translation allowed colonization of vertebrate hosts. J. Virol. 86, 9484-9494 (2012).

21. Ventoso, I. et al. Translational resistance of late alphavirus mRNA to elF2alpha phosphorylation: a strategy to overcome the antiviral effect of protein kinase PKR. Genes Dev. 20, 87-100 (2006).

22. Sanz, M. A., Gonzalez Almela, E. \& Carrasco, L. Translation of sindbis subgenomic mRNA is independent of elF2, elF2A and elF2D. Sci. Rep. 7 43876 (2017).

23. Toribio, R., Diaz-Lopez, I., Boskovic, J. \& Ventoso, I. An RNA trapping mechanism in Alphavirus mRNA promotes ribosome stalling and translation initiation. Nucleic Acids Res. 44, 4368-4380 (2016).

24. Jha, S. et al. Trans-kingdom mimicry underlies ribosome customization by a poxvirus kinase. Nature 546, 651-655 (2017).

25. Vachon, V. K. \& Conn, G. L. Adenovirus VA RNA an essential pro-viral non-coding RNA. Virus Res. 212 39-52 (2016)

26. Iwakiri, D. Multifunctional non-coding Epstein-Barr virus encoded RNAs (EBERs) contribute to viral pathogenesis. Virus Res. 212, 30-38 (2016).

27. Mailliot, J. \& Martin, F. Viral internal ribosomal entry sites: four classes for one goal. Wiley Interdiscip. Rev. RNA 9, e1458 (2018).

28. Asnani, M., Kumar, P. \& Hellen, C. U. Widespread distribution and structural diversity of Type IV IRESs in members of Picornaviridae. Virology 478, 61-74 (2015). This study describes the diversity of a type of IRES and illustrates how useful and adaptable this type of RNA element and mechanism must be.

29. Filbin, M. E. \& Kieft, J. S. Toward a structural understanding of IRES RNA function. Curr. Opin. Struct. Biol. 19, 267-276 (2009).

30. Kerr, C. H. \& Jan, E. Commandeering the ribosome: lessons learned from dicistroviruses about translation J. Virol. 90, 5538-5540 (2016).

31. Hertz, M. I. \& Thompson, S. R. Mechanism of translation initiation by Dicistroviridae IGR IRESs. Virology 411, 355-361 (2011).

32. Colussi, T. M. et al. Initiation of translation in bacteria by a structured eukaryotic IRES RNA. Nature 519, 110-113 (2015)

33. Pfingsten, J. S., Costantino, D. A. \& Kieft, J. S. Structural basis for ribosome recruitment and manipulation by a viral IRES RNA. Science 314 1450-1454 (2006).
34. Schuler, M. et al. Structure of the ribosome-bound cricket paralysis virus IRES RNA. Nat. Struct. Mol. Biol. 13, 1092-1096 (2006).

35. Spahn, C. M. et al. Cryo-EM visualization of a viral internal ribosome entry site bound to human ribosomes: the IRES functions as an RNA-based translation factor. Cell 118, 465-475 (2004).

36. Zhu, J. et al. Crystal structures of complexes containing domains from two viral internal ribosome entry site (IRES) RNAs bound to the 70 S ribosome. Proc. Natl Acad. Sci. USA 108 1839-1844 (2011).

37. Butcher, S. E. \& Jan, E. tRNA-mimicry in IRESmediated translation and recoding. RNA Biol. 13 1068-1074 (2016).

38. Costantino, D. A., Pfingsten, J. S., Rambo, R. P. $\&$ Kieft, J. S. tRNA-mRNA mimicry drives translation initiation from a viral IRES. Nat. Struct. Mol. Biol. 15, 57-64 (2007)

39. Fernandez, J., Yaman, I., Sarnow, P., Snider, M. D. \& Hatzoglou, M. Regulation of internal ribosomal entry site-mediated translation by phosphorylation of the translation initiation factor elF2 $\alpha$. J. Biol. Chem. 277, 19198-19205 (2002).

40. Muhs, M. et al. Cryo-EM of ribosomal $80 \mathrm{~S}$ complexes with termination factors reveals the translocated cricket paralysis virus IRES. Mol. Cell 57, 422-432 (2015).

41. Fernández, I. S., Bai, X.-C., Murshudov, G., Scheres, S. H. W. \& Ramakrishnan, V. Initiation of translation by cricket paralysis virus IRES requires its translocation in the ribosome. Cell 157, 823-831 (2014).

42. Ruehle, M. D. et al. A dynamic RNA loop in an IRES affects multiple steps of elongation factormediated translation initiation. eLife 4, e08146 (2015).

43. Abeyrathne, P. D., Koh, C. S., Grant, T., Grigorieff, N. \& Korostelev, A. A. Ensemble cryo-EM uncovers inchworm-like translocation of a viral IRES through the ribosome. eLife 5, e14874 (2016).

Using cryo-EM, this study uncovers the structures of multiple states of class 4 IRES translation initiation events, showing that conformational rearrangements allow it to transit the ribosome during translation initiation.

44. Martínez-Salas, E., Francisco-Velilla, R. Fernandez-Chamorro, J., Lozano, G. $\delta$ Diaz-Toledano, R. Picornavirus IRES elements: RNA structure and host protein interactions. Virus Res. 206, 62-73 (2015).

45. Robert, F. et al. Initiation of protein synthesis by hepatitis $C$ virus is refractory to reduced eIF2.GTP. Met-tRNA(i)(Met) ternary complex availability. Mol. Biol. Cell 17, 4632-4644 (2006)

46. Jaafar, Z. A., Oguro, A., Nakamura, Y. \& Kieft, J. S. Translation initiation by the hepatitis $C$ virus IRES requires elF1 $\mathrm{A}$ and ribosomal complex remodeling. elife 5, e21198 (2016)

47. Terenin, I. M., Dmitriev, S. E., Andreev, D. E. \& Shatsky, I. N. Eukaryotic translation initiation machinery can operate in a bacterial-like mode 
without elF2. Nat. Struct. Mol. Biol. 15, 836-841 (2008).

This paper presents a mechanistic study of the ability of the HCV IRES to recruit tRNA to the 40S subunit without using eIF2.

48. Pestova, T. V., de Breyne, S., Pisarev, A. V., Abaeva, I. S $\&$ Hellen, C. U. elF2-dependent and elF2-independent modes of initiation on the CSFV IRES: a common role of domain II. EMBO J. 27, 1060-1072 (2008).

49. Quade, N., Boehringer, D., Leibundgut, M., van den Heuvel, J. \& Ban, N. Cryo-EM structure of hepatitis C virus IRES bound to the human ribosome at $3.9-\AA$ resolution. Nat. Commun. 6, 7646 (2015).

50. Yamamoto, H. et al. Structure of the mammalian $80 \mathrm{~S}$ initiation complex with initiation factor 5B on $\mathrm{HCV}$ IRES RNA. Nat. Struct. Mol. Biol. 21, 721-727 (2014). This study presents a cryo-EM structure offering key insights into the later steps in HCV IRESmediated translation initiation and functions of eIF5B after subunit joining

51. Hashem, Y. et al. Hepatitis-C-virus-like internal ribosome entry sites displace elF3 to gain access to the 40 S subunit. Nature 503, 539-543 (2013).

52. Khawaja, A., Vopalensky, V. \& Pospisek, M Understanding the potential of hepatitis $C$ virus internal ribosome entry site domains to modulate translation initiation via their structure and function Wiley Interdiscip. Rev. RNA 6, 211-224 (2015).

53. Pestova, T. V., Shatsky, I. N., Fletcher, S. P., Jackson, R. J. \& Hellen, C. U. A prokaryotic-like mode of cytoplasmic eukaryotic ribosome binding to the initiation codon during internal translation initiation of hepatitis $\mathrm{C}$ and classical swine fever virus RNAs. Genes Dev. 12 67-83 (1998)

This seminal study establishes direct binding of the HCV (and related IRESs) to the 40 S subunit and the set of factors needed for initiation to occur on the IRES

54. Kieft, J. S., Zhou, K., Jubin, R. \& Doudna, J. A Mechanism of ribosome recruitment by hepatitis $C$ IRES RNA. RNA 7, 194-206 (2001).

55. Filbin, M. E., Vollmar, B. S., Shi, D., Gonen, T. \& Kieft, J. S. HCV IRES manipulates the ribosome to promote the switch from translation initiation to elongation. Nat. Struct. Mol. Biol. 20, 150-158 (2012).

56. Filbin, M. E. \& Kieft, J. S. HCV IRES domain Ilb affects the configuration of coding RNA in the 40S subunit's decoding groove. RNA 17, 1258-1273 (2011).

57. Locker, N., Easton, L. E. \& Lukavsky, P. J. HCV and CSFV IRES domain II mediate eIF2 release during 805 ribosome assembly. EMBO J. 26, 795-805 (2007).

58. Spahn, C. M. et al. Hepatitis $C$ virus IRES RNAinduced changes in the conformation of the $40 \mathrm{~S}$ ribosomal subunit. Science 291, 1959-1962 (2001). This study provides the first 3D view of an IRES bound to a ribosomal subunit, establishing this IRES as an active manipulator of ribosome structure.

59. Kim, J. H., Park, S. M., Park, J. H., Keum, S.J. $\Sigma$ Jang, S. K. elF2A mediates translation of hepatitis $C$ viral mRNA under stress conditions. EMBO J. 30 2454-2464 (2011).

60. Skabkin, M. A. et al. Activities of Ligatin and MCT-1/ DENR in eukaryotic translation initiation and ribosomal recycling. Genes Dev. 24, 1787-1801 (2010)

61. Dmitriev, S. E. et al. GTP-independent tRNA delivery to the ribosomal P-site by a novel eukaryotic translation factor. J. Biol. Chem. 285, 26779-26787 (2010)

62. de Breyne, S., Yu, Y., Pestova, T. V. \& Hellen, C. U. T. Factor requirements for translation initiation on the Simian picornavirus internal ribosomal entry site. $R N A$ 14, 367-380 (2007)

This detailed biochemical study of a class 3 IRES suggests the possibility of factor-independent and initiator tRNA delivery.

63. King, H. A., Cobbold, L. C. \& Willis, A. E. The role of IRES trans-acting factors in regulating translation initiation. Biochem. Soc. Trans. 38, 1581-1586 (2010)

64. Lozano, G. \& Martínez-Salas, E. Structural insights into viral IRES-dependent translation mechanisms. Curr Opin Virol 12, 113-120 (2015).

65. Meurs, E. F. et al. Constitutive expression of human double-stranded RNA-activated p68 kinase in murine cells mediates phosphorylation of eukaryotic initiation factor 2 and partial resistance to encephalomyocarditis virus growth $J$. Virol. 66 , 5805-5814 (1992).

66. White, J. P., Reineke, L. C. \& Lloyd, R. E. Poliovirus switches to an elF2-independent mode of translation during infection. J. Virol. 85, 8884-8893 (2011).
67. Kafasla, P. et al. Polypyrimidine tract binding protein stabilizes the encephalomyocarditis virus IRES structure via binding multiple sites in a unique orientation. Mol. Cell 34, 556-568 (2009). This article provides an illustration of the paradigm that ITAFs affect IRES structure to allow translation machinery to bind.

68. Borovjagin, A., Pestova, T. \& Shatsky, I. Pyrimidine tract binding protein strongly stimulates in vitro encephalomyocarditis virus RNA translation at the level of preinitiation complex formation. FEBS Lett. 351, 299-302 (1994).

69. Kafasla, P., Morgner, N., Robinson, C. V. \& Jackson, R. J. Polypyrimidine tract-binding protein stimulates the poliovirus IRES by modulating elF4C binding. EMBO J. 29, 3710-3722 (2010).

70. Sweeney, T. R., Abaeva, I. S., Pestova, T V. $\&$ Hellen, C. U. T. The mechanism of translation initiation on type 1 picornavirus IRESs. EMBO J. 33 76-92 (2013).

71. Fernandez-Miragall, O., Ramos, R., Ramajo, J. $\&$ Martnez-Salas, E. Evidence of reciprocal tertiary interactions between conserved motifs involved in organizing RNA structure essential for internal initiation of translation. RNA 12, 223-234 (2005)

72. Fernandez, N. et al. Structural basis for the biological relevance of the invariant apical stem in IRESmediated translation. Nucleic Acids Res. 39 , 8572-8585 (2011)

73. Fernandez-Miragall, O. \& Martnez-Salas, E. Structural organization of a viral IRES depends on the integrity of the GNRA motif. RNA 9, 1333-1344 (2003).

74. Kolupaeva V. G Pestova, T. V., Hellen C. U. \& Shatsky, I. N. Translation eukaryotic initiation factor $4 \mathrm{G}$ recognizes a specific structural element within the internal ribosome entry site of encephalomyocarditis virus RNA. J. Biol. Chem. 273, 18599-18604 (1998)

75. de Quinto, S. L., Lafuente, E. \& Martnez-Salas, E. IRES interaction with translation initiation factors: functional characterization of novel RNA contacts with elF3, elF4B and elF4GII. RNA 7, 1213-1226 (2001).

76. Kaminski, A., Belsham, G. J. ¿ Jackson, R. J. Translation of encephalomyocarditis virus RNA parameters influencing the selection of the internal initiation site. EMBO J. 13, 1673-1681 (1994).

77. Lopez de Quinto, S. \& Martinez-Salas, E. Involvement of the aphthovirus RNA region located between the two functional AUGs in start codon selection. Virology 255, 324-336 (1999)

78. Pilipenko, E. V. et al. Prokaryotic-like cis elements in the cap-independent internal initiation of translation on picornavirus RNA. Cell 68, 119-131 (1992).

79. Pelletier, J. \& Sonenberg, N. Internal initiation of translation of eukaryotic mRNA directed by a sequence derived from poliovirus RNA. Nature 334 320-325 (1988)

This study is the first to characterize the existence of an IRES in poliovirus and report the first methods used to validate IRES function.

80. Du, Z., Ulyanov, N. B., Yu, J., Andino, R. \& James, T. L. NMR structures of loop B RNAs from the stem-loop IV domain of the enterovirus internal ribosome entry site: a single $\mathrm{C}$ to $\mathrm{U}$ substitution drastically changes the shape and flexibility of RNA. Biochemistry 43 , 5757-5771 (2004).

81. Imai, S., Kumar, P., Hellen, C. U., D’Souza, V. M. \& Wagner, G. An accurately preorganized IRES RNA structure enables elF4G capture for initiation of viral translation. Nat. Struct. Mol. Biol. 23, 859-864 (2016).

82. Abaeva, I. S., Pestova, T. V. \& Hellen, C. U. T. Attachment of ribosomal complexes and retrograde scanning during initiation on the Halastavi arva virus IRES. Nucleic Acids Res. 44, 2362-2377 (2016). This paper presents a description of an IRES that uses an unusual form of retrograde scanning to position a start codon

83. Plank, T.-D. M., Whitehurst, J. T. \& Kieft, J. S. Cell type specificity and structural determinants of IRES activity from the 5' leaders of different HIV-1 transcripts. Nucleic Acids Res. 41, 6698-6714 (2013).

84. Ohlmann, T., Mengardi, C. \& Lopez-Lastra, M. Translation initiation of the HIV-1 mRNA. Translation 2, e960242 (2014).

85. Smirnova, V. V. et al. Does HIV-1 mRNA 5 '-untranslated region bear an internal ribosome entry site? Biochimie 121, 228-237 (2015).

86. Murat, P. et al. G-Quadruplexes regulate Epstein-Barr virus-encoded nuclear antigen 1 mRNA translation. Nat. Chem. Biol. 10, 358-364 (2014).

87. Caliskan, N., Peske, F. \& Rodnina, M. V. Changed in translation: mRNA recoding by -1 programmed ibosomal frameshifting. Trends Biochem. Sci.40, 265-274 (2015)

88. Dinman, J. D. Mechanisms and implications of programmed translational frameshifting. Wiley Interdiscip. Rev. RNA 3, 661-673 (2012).

89. Plant, E. P. \& Dinman, J. D. Comparative study of the effects of heptameric slippery site composition on -1 frameshifting among different eukaryotic systems. RNA 12, 666-673 (2006).

This study provides a systematic analysis of the contribution of the 'slippery' sequence to frameshifting and how that contribution varies between sequences and among ribosomes from distinct eukaryotic sources.

90. Ishimaru, D. et al. RNA dimerization plays a role in ribosomal frameshifting of the SARS coronavirus. Nucleic Acids Res. 41, 2594-2608 (2013).

91. Marcheschi, R. J., Staple, D. W. \& Butcher, S. E. Programmed ribosomal frameshifting in SIV is induced by a highly structured RNA stem-loop. J. Mol. Biol. 373, 652-663 (2007).

92. Gaudin, C. et al. Structure of the RNA signal essentia for translational frameshifting in HIV-1. J. Mol. Biol. 349, 1024-1035 (2005)

93. Biswas, P., Jiang, X., Pacchia, A. L., Dougherty, J. P. \& Peltz, S. W. The human immunodeficiency virus type 1 ribosomal frameshifting site is an invariant sequence determinant and an important target for antiviral therapy. J. Virol. 78, 2082-2087 (2004)

94. Gao, F. \& Simon, A. E. Multiple cis-acting elements modulate programmed - 1 ribosomal frameshifting in pea enation mosaic virus. Nucleic Acids Res. 44 878-895 (2016).

This article provides a fascinating example of how a combination of folded RNAs can be used to create a complex regulation strategy.

95. Moomau, C., Musalgaonkar, S., Khan, Y. A., Jones, J. E. $\ltimes$ Dinman, J. D. Structural and functional characterization of programmed ribosomal frameshift signals in West Nile virus strains reveals high structural plasticity among cis-acting rna elements. J. Biol. Chem. 291, 15788-15795 (2016).

96. Ritchie, D. B., Foster, D. A. \& Woodside, M. T. Programmed - 1 frameshifting efficiency correlates with RNA pseudoknot conformational plasticity, not resistance to mechanical unfolding. Proc. Natl Acad. Sci. USA 109, 16167-16172 (2012).

97. Mouzakis, K. D., Lang, A. L., Vander Meulen, K. A., Easterday, P. D. \& Butcher, S. E. HIV-1 frameshift efficiency is primarily determined by the stability of base pairs positioned at the mRNA entrance channel of the ribosome. Nucleic Acids Res. 41, 1901-1913 (2013).

This study demonstrates the importance of thermodynamic stability in certain parts of an RNA element to create a specific translation recoding event.

98. Chen, J. et al. Dynamic pathways of - 1 translational frameshifting. Nature 512, 328-332 (2014). This paper presents a quantitative cutting-edge biophysical study of the mechanics of frameshifting on bacterial ribosomes.

99. Takyar, S., Hickerson, R. P. \& Noller, H. F. mRNA helicase activity of the ribosome. Cell 120, 49-58 (2005).

100. Li, Y. et al. Transactivation of programmed ribosomal frameshifting by a viral protein. Proc. Natl Acad. Sci. USA 111, E2172-E2181 (2014).

101. Fang, Y. et al. Efficient -2 frameshifting by mammalian ribosomes to synthesize an additional arterivirus protein. Proc. Natl Acad. Sci. USA 109 E2920-E2928 (2012)

102. Napthine, S. et al. A novel role for poly(C) binding proteins in programmed ribosomal frameshifting. Nucleic Acids Res. 44, 5491-5503 (2016).

103. Finch, L. K. et al. Characterization of ribosomal frameshifting in theiler's murine encephalomyelitis virus. J. Virol. 89, 8580-8589 (2015).

104. Napthine, S. et al. Protein-directed ribosomal frameshifting temporally regulates gene expression. Nat. Commun. 8, 15582 (2017)

105. Loughran, G., Firth, A. E. \& Atkins, J. F. Ribosomal frameshifting into an overlapping gene in the 2B-encoding region of the cardiovirus genome. Proc. Natl Acad. Sci. USA 108, E1111-E1119 (2011)

106. Tork, S., Hatin, I., Rousset, J. P. \& Fabret, C. The major 5 ' determinant in stop codon read-through involves two adjacent adenines. Nucleic Acids Res. 32, 415-421 (2004)

107. Namy, O., Hatin, I. \& Rousset, J. P. Impact of the six nucleotides downstream of the stop codon on translation termination. EMBO Rep. 2, 787-793 (2001). 
108. Cassan, M. \& Rousset, J. P. UAG readthrough in mammalian cells: effect of upstream and downstream stop codon contexts reveal different signals. BMC Mol. Biol. 2 , 3 (2001).

109. Harrell, L., Melcher, U. \& Atkins, J. F. Predominance of six different hexanucleotide recoding signals 3 ' of read-through stop codons. Nucleic Acids Res. 30 2011-2017 (2002)

110. Skuzeski, J. M., Nichols, L. M., Gesteland, R. F. \& Atkins, J. F. The signal for a leaky UAG stop codon in several plant viruses includes the two downstream codons. J. Mol. Biol. 218, 365-373 (1991).

111. Firth, A. E., Wills, N. M., Gesteland, R. F. \& Atkins, J. F. Stimulation of stop codon readthrough: frequent presence of an extended 3' RNA structural element. Nucleic Acids Res. 39, 6679-6691 (2011)

112. Napthine, S., Yek, C., Powell, M. L., Brown, T. D. K $\&$ Brierley, I. Characterization of the stop codon readthrough signal of Colorado tick fever virus segment 9 RNA. RNA 18, 241-252 (2011).

113. Houck-Loomis, B. et al. An equilibrium-dependent retroviral mRNA switch regulates translational recoding. Nature 480, 561-564 (2011).

114. Wills, N. M., Gesteland, R. F. \& Atkins, J. F. Evidence that a downstream pseudoknot is required for translational read-through of the Moloney murine leukemia virus gag stop codon. Proc. Natl Acad. SCi. USA 88, 6991-6995 (1991)

115. Cimino, P. A., Nicholson, B. L., Wu, B., Xu, W. $\&$ White, K. A. Multifaceted regulation of translational readthrough by RNA replication elements in a tombusvirus. PLOS Pathog. 7 e1002423 (2011)

116. Kuhlmann, M. M., Chattopadhyay, M., Stupina, V. A., Gao, F. \& Simon, A. E. An RNA element that facilitates programmed ribosomal readthrough in turnip crinkle virus adopts multiple conformations. J. Virol. 90 , 8575-8591 (2016).

This paper provides an example of how conformational changes in RNA influence biological function.

117. Beier, H. \& Grimm, M. Misreading of termination codons in eukaryotes by natural nonsense suppressor tRNAs. Nucleic Acids Res. 29, 4767-4782 (2001)

118. Meyers, G. Characterization of the sequence element directing translation reinitiation in RNA of the calicivirus rabbit hemorrhagic disease virus. J. Virol. 81, 9623-9632 (2007)

119. Luttermann, C. \& Meyers, G. A bipartite sequence motif induces translation reinitiation in feline calicivirus RNA. J. Biol. Chem. 282, 7056-7065 (2007).

120. McCormick, C. J., Salim, O., Lambden, P. R. \& Clarke, I. N. Translation termination reinitiation between open reading frame 1 (ORF1) and ORF2 enables capsid expression in a bovine norovirus without the need for production of viral subgenomic RNA. J. Virol. 82, 8917-8921 (2008).

121. Luttermann, C. \& Meyers, G. The importance of interand intramolecular base pairing for translation reinitiation on a eukaryotic bicistronic mRNA. Genes Dev. 23, 331-344 (2009).

122. Zinoviev, A., Hellen, C. U. T. \& Pestova, T. V. Multiple mechanisms of reinitiation on bicistronic calicivirus mRNAs. Mol. Cell 57, 1059-1073 (2015).

123. Nicholson, B. L. \& White, K. A. 3' cap-independent translation enhancers of positive-strand RNA plant viruses. Curr. Opin. Virol. 1, 373-380 (2011).

124. Simon, A. E. \& Miller, W. A. 3' cap-independent translation enhancers of plant viruses. Annu. Rev. Microbiol. 67, 21-42 (2013).

125. Miras, M., Miller, W. A., Truniger, V. \& Aranda, M. A Non-canonical translation in plant RNA viruses. Front. Plant Sci. 8, 494 (2017).

This article reports on a recent discovery of a nove class of viral 3 '-CITE shared between viral families by recombination.

126. Truniger, V., Miras, M. \& Aranda, M. A. Structural and functional diversity of plant virus 3'-cap-independent translation enhancers (3'-CITEs). Front. Plant. Sci. 8 2047 (2017)

This paper provides an excellent recent review of 3 -CITE diversity and structure.

127. Guo, L., Allen, E. \& Miller, W. A. Structure and function of a cap-independent translation element that functions in either the $3^{\prime}$ or the $5^{\prime}$ untranslated region. RNA 6, 1808-1820 (2000)

128. Guo, L., Allen, E. M. \& Miller, W. A. Base-pairing between untranslated regions facilitates translation of uncapped, nonpolyadenylated viral RNA. Mol. Cell 7 , 1103-1109 (2001)

129. Rakotondrafara, A. M., Polacek, C., Harris, E. \& Miller, W. A. Oscillating kissing stem-loop interactions mediate 5 ' scanning-dependent translation by a viral 3'-cap-independent translation element. RNA 12 1893-1906 (2006)

130. Nicholson, B. L., Wu, B., Chevtchenko, I. \& White, K. A Tombusvirus recruitment of host translational machinery via the 3' UTR. RNA 16, 1402-1419 (2010).

131. Wang, S., Browning, K. S. \& Miller, W. A. A viral sequence in the 3'-untranslated region mimics a 5 ' cap in facilitating translation of uncapped mRNA. EMBO J. 16, 4107-4116 (1997)

132. Gazo, B. M., Murphy, P., Gatchel, J. R. \& Browning, K. S A novel interaction of Cap-binding protein complexes eukaryotic initiation factor (elF) $4 \mathrm{~F}$ and elF(iso) $4 \mathrm{~F}$ with a region in the 3 -untranslated region of satellite tobacco necrosis virus. J. Biol. Chem. 279, 13584-13592 (2004).

133. Miller, W. A., Wang, Z. \& Treder, K. The amazing diversity of cap-independent translation elements in the 3'-untranslated regions of plant viral RNAs. Biochem. Soc. Trans. 35, 1629-1633 (2007).

134. Meulewaeter, F. et al. Conservation of RNA structures enables TNV and BYDV 5' and 3' elements to cooperate synergistically in cap-independent translation. Nucleic Acids Res. 32, 1721-1730 (2004).

135. Fan, Q., Treder, K. \& Miller, W. A. Untranslated regions of diverse plant viral RNAs vary greatly in translation enhancement efficiency. Biochem. Soc. Trans. 12, 22 (2012).

136. Wang, S. \& Miller, W. A. A sequence located 4.5 to 5 kilobases from the 5 ' end of the barley yellow dwarf virus (PAV) genome strongly stimulates translation of uncapped mRNA. J. Biol. Chem. 270, 13446-13452 (1995).

137. Wang, Z Kraft, J. J., Hui, A. Y \& Miller, W. A. Structural plasticity of Barley yellow dwarf virus-like cap-independent translation elements in four genera of plant viral RNAs. Virology 402, 177-186 (2010).

138. Das Sharma, S., Kraft, J. J. Miller, W. A. \& Goss, D. J. Recruitment of the 40S ribosome subunit to the 3 '-untranslated region (UTR) of a viral mRNA, via the elF4 complex, facilitates cap-independent translation. J. Biol. Chem. 290, 11268-11281 (2015).

139. Kraft, J. J., Treder, K., Peterson, M. S. \& Miller, W. A. Cation-dependent folding of 3 ' cap-independent translation elements facilitates interaction of a 17-nucleotide conserved sequence with elF4G. Nucleic Acids Res. 41, 3398-3413 (2013).

140. Zhao, P., Liu, O., Miller, W. A. \& Goss, D. J. Eukaryotic translation initiation factor $4 \mathrm{G}$ (elF4G) coordinates interactions with elF4A, elF4B, and elF4E in binding and translation of the barley yellow dwarf virus 3' capindependent translation element (BTE). J. Biol. Chem. 292, 5921-5931 (2017)

This article presents an in-depth quantitative exploration of the interactions underlying recruitment of translation factors to a 3 '-CITE.

141. Batten, J. S., Desvoyes, B., Yamamura, Y. $\&$ Scholthof, K.-B. G. A translational enhancer element on the 3'-proximal end of the Panicum mosaic virus genome. FEBS Lett. 580, 2591-2597 (2006).

142. Wang, Z., Treder, K. \& Miller, W. A. Structure of a viral cap-independent translation element that functions via high affinity binding to the elF4E subunit of elF4F. J. Biol. Chem. 284, 14189-14202 (2009).

143. Liu, Q. \& Goss, D. J. Understanding the role of pea enation mosaic virus mRNA $3^{\prime}$ untranslated region in translation initiation [abstract]. FASEB J. 28 (Suppl. 1), 566.5 (2014)

144. Wang, Z., Parisien, M., Scheets, K. \& Miller, W. A. The cap-binding translation initiation factor, elF4E, binds a pseudoknot in a viral cap-independent translation element. Structure 19, 868-880 (2011).

This study provides a detailed characterization of a 3 '-CITE that binds eIF4E, with a compelling structural model for how this occurs.

145. Stupina, V. A. et al. The 3' proximal translational enhancer of Turnip crinkle virus binds to $60 \mathrm{~S}$ ribosomal subunits. RNA 14, 2379-2393 (2008).

146. McCormack, J. C. et al. Structural domains within the 3 ' untranslated region of Turnip crinkle virus. J. Virol. 82, 8706-8720 (2008)

147. Stupina, V. A., Yuan, X., Meskauskas, A., Dinman, J. D. $\&$ Simon, A. E. Ribosome binding to a $5^{\prime}$ translational enhancer is altered in the presence of the $3^{\prime}$ untranslated region in cap-independent translation of turnip crinkle virus. J. Virol. 85, 4638-4653 (2011).

148. Gao, F. \& Simon, A. E. Differential use of 3'CITEs by the subgenomic RNA of Pea enation mosaic virus 2 Virology 510, 194-204 (2017).

149. Gao, F., Kasprzak, W. K., Szarko, C., Shapiro, B. A. \& Simon, A. E. The 3 ' untranslated region of pea enation mosaic virus contains two T-shaped, ribosome-binding, cap-independent translation enhancers. J. Virol $\mathbf{8 8}$ 11696-11712 (2014).

This paper presents an illustration of how plant virus 3'-CITEs can exist in multiple copies as part of a complex translation initiation regulation strategy.

150. Du, Z., Alekhina, O. M., Vassilenko, K. S. \& Simon, A. E. Concerted action of two $3^{\prime}$ cap-independent translation enhancers increases the competitive strength of translated viral genomes. Nucleic Acids Res. 45 9558-9572 (2017).

Related to reference 152, this study shows how a combination of $3^{\prime}$-CITEs can work together in a complex way to increase the success of the virus.

151. Zuo, X. et al. Solution structure of the cap-independent translational enhancer and ribosome-binding element in the 3' UTR of turnip crinkle virus. Proc. Natl Acad. Sci. USA 107, 1385-1390 (2010).

152. Yuan, X., Shi, K., Meskauskas, A. \& Simon, A. E. The 3 end of Turnip crinkle virus contains a highly interactive structure including a translational enhancer that is disrupted by binding to the RNA-dependent RNA polymerase. RNA 15, 1849-1864 (2009).

153. Le, M. T. et al. Folding behavior of a T-shaped, ribosome-binding translation enhancer implicated in a wide-spread conformational switch. eLife 6, e22883 (2017).

154. Dreher, T. W. Viral tRNAs and tRNA-like structures. Wiley Interdiscip. Rev. RNA 1, 402-414 (2010).

155. Dreher, T. W., Uhlenbeck, O. C. \& Browning, K. S Quantitative assessment of EF-1 alpha. GTP binding to aminoacyl-tRNAs, aminoacyl-viral RNA, and tRNA shows close correspondence to the RNA binding properties of EF-Tu. J. Biol. Chem. 274, 666-672 (1999). This quantitative assessment of the binding of a viral TLS to elF1 A demonstrates endogenous tRNAlike affinity and supports its importance to the virus.

156. Colussi, T. M. et al. The structural basis of transfer RNA mimicry and conformational plasticity by a viral RNA. Nature 511, 366-369 (2014). This article presents a crystal structure of a viral TLS showing an overall tRNA-like but structurally distinct fold that presents key insights into aminoacylation as well as accessibility for replication.

157. Hammond, J. A., Rambo, R. P. \& Kieft, J. S. Multi-domain packing in the aminoacylatable 3 ' end of a plant viral RNA. J. Mol. Biol. 399, 450-463 (2010).

158. Barends, S., Bink, H. H., van den Worm, S. H. Pleij, C. W. \& Kraal, B. Entrapping ribosomes for viral translation: tRNA mimicry as a molecular Trojan horse Cell 112, 123-129 (2003).

159. Matsuda, D. \& Dreher, T. W. Cap- and initiator tRNAdependent initiation of TYMV polyprotein synthesis by ribosomes: evaluation of the Trojan horse model for TYMV RNA translation. RNA 13, 129-137 (2006)

160. Shen, L. X. \& Tinoco, I. Jr. The structure of an RNA pseudoknot that causes efficient frameshifting in mouse mammary tumor virus. J. Mol. Biol. 247 , 963-978 (1995).

161. Chattopadhyay, M., Shi, K., Yuan, X. \& Simon, A. E. Long-distance kissing loop interactions between a $3^{\prime}$ proximal Y-shaped structure and apical loops of 5 hairpins enhance translation of Saguaro cactus virus. Virology 417, 113-125 (2011).

\section{Acknowledgements}

The authors thank D. Costantino for critical reading of this manuscript. Viral RNA research in the Kieft laboratory is supported by US National Institutes of Health grants R35GM118070, R21Al129569, R01Al133348 and P01Al1 20943 (J.S.K.)

\section{Author contributions}

Z.A.J. researched data for the article. Z.A.J. and J.S.K. wrote the manuscript together

\section{Competing interests}

The authors declare no competing interests.

\section{Publisher's note}

Springer Nature remains neutral with regard to jurisdictional claims in published maps and institutional affiliations.

\section{Reviewer information}

Nature Reviews Microbiology thanks C. Hellen, A. Simon, and other anonymous reviewer(s), for their contribution to the peer review of this work.

RELATED LINKS

RCSB Protein Databank: http://www.rcsb.org/pdb/home/ 